\title{
EL ESTADO AUTONÓMICO TREINTA AÑOS DESPUÉS: ENSAYO DE UNA VALORACIÓN
}

\author{
JOSÉ TUDELA ARANDA \\ Letrado de las Cortes de Aragón
}

\section{SUMARIO}

I. Presentación.

II. Un presupuesto ineludible. Los términos del debate sobre la organización territorial en el proceso constituyente.

III. Dialécticas y evolución en el Estado autonómico hasta el año 2000.

IV. La fractura de un modelo: los Estatutos de Autonomía de segunda generación como reflejo y expresión de una mutación constitucional.

V. El Estado resultante. Organización territorial y capacidad del Estado.

VI. A modo de conclusión Un ensayo de evaluación valorativa.

\section{PRESENTACIÓN}

Hace ya más de treinta años que se aprobó la Constitución vigente. Entre sus contenidos, el referido a la organización territorial era uno de los más abiertos ${ }^{1}$. Transcurrido ese tiempo, no es discutible que sigue siendo un capítulo sin cerrar del desarrollo constitucional. No es que no haya sucedido nada. Al revés, han sucedido muchas cosas en la dinámica territorial del poder. Hasta el punto de que pocos contenidos del texto constitucional se acercarán tanto a la mutación como éste. Por ello, pare-

1 Como es conocido, tempranamente el profesor Cruz Villalón describió el modelo de organización territorial como desconstitucionalizado (P. CRUZ VILLALÓN, La estructura del Estado o la curiosidad del jurista persa, Revista de la Facultad de Derecho de la Universidad Complutense n. ${ }^{\circ} 4$, 1991).

UNED. Teoria y Realidad Constitucional, núm. 24, 2009, pp. 191-242. 
ce conveniente realizar un ejercicio de memoria que no rehuya la valoración.

Los análisis jurídicos son imprescindibles. Más que nunca es necesario reivindicar el Derecho y su importancia en la construcción ordenada de un Estado. Pero la evaluación que se desea abordar exige algo más. Desde luego, presupuestos políticos sin los cuales sería imposible entender gran cosa. El territorio de fusión de la política con el Derecho es el del Derecho Constitucional. La necesaria juridificación del poder. Ahora bien, en la hora de una valoración final, derecho y política exigen de un esfuerzo intelectual que los enriquezca. También del ejercicio activo de la ciudadanía ${ }^{2}$. Valorar lo sucedido es presupuesto esencial de futuro. Una valoración que si quiere servir a ese futuro debe mirar esencialmente a los errores cometidos. Los aciertos y los éxitos existen y son importantes. Pero nada se avanzará recreándose en ellos. Sin olvidarlos, parece preciso centrar esfuerzos en la detección de los problemas como premisa de un próximo debate que en estas páginas se entiende ineludible.

Comprender el presente del Estado autonómico y entender mejor sus problemas exige hoy imperiosamente de una lectura histórica. Éste será el objeto de la primera parte de este trabajo, distinguiendo dos fases que por si mismas resultan de gran relevancia. La historia, necesariamente, apenas ha transcurrido el tiempo, nos trae rápidamente al presente. Un presente que es, simultáneamente, historia, derecho, política y futuro y que exige un notable esfuerzo de transcendencia. El análisis de ese presente mediante el intento de descripción del significado de la segunda generación de Estatutos de Autonomía constituirá la segunda parte del trabajo. La descripción del Estado resultante, con singular referencia a aquello que de poder público permanece en las instancias centrales del Estado y la determinación de los principales interrogantes, constituirán la tercera y última parte de estas páginas.

Se dijo en el inicio de estas palabras que el presente exige de un esfuerzo intelectual que transcienda los términos del debate más mediático y cotidiano. Es evidente que ese esfuerzo escapa a la posibilidad de estas páginas. Pero los treinta años transcurridos y las premisas del debate más contemporáneo facilitan un ejercicio de reflexión que desde los presupuestos que el derecho ha aportado reflejen dudas, interrogantes y reflexiones. No se persigue extraer grandes conclusiones ni siquiera realizar disecciones jurídicas más o menos exhaustivas. Estas líneas sólo buscan aportar una reflexión que pueda contribuir a entender mejor el tiempo transcurrido.

Una última consideración que quiere ayudar a comprender el tono de estas páginas. Nadie escribe ni piensa ajeno a su experiencia personal. Mi labor profesional se ha desarrollado por entero en un Parlamento autonómico, las Cortes de Aragón, y desde esa posición se realizarán, necesariamente,

2 Esta visión se reivindica desde las páginas del excelente trabajo del profesor Pemán Gavín, (J. PEMÁN GAVÍN, El sistema español de autonomías territoriales. Apuntes para un diagnóstico, www.fundacionmgimenezabad.es, 2009, pág. 2). 
mis consideraciones sobre la evolución de la forma de organización territorial del poder prevista en la Constitución. Junto a ello, aunque resulte obvio, he perseguido una valoración alejada de los condicionantes impuestos por la lucha política española. La visión del político es demasiadas veces reduccionista, excesivamente condicionada por los fragores de la batalla electoral. Pero sí he considerado precisa esta obviedad no es para subrayar lugares comunes. La desmedida tensión política acumulada sobre el debate territorial y la lejanía de cualquier distancia razonable, ha enquistado no sólo el estricto debate político sino que ha contaminado, en demasiadas ocasiones más allá de lo inevitable, el debate académico. Por ello, es preciso decir, y paradójicamente la premisa se convierte en conclusión, que las posiciones críticas, en positivo o negativo, sobre lo acaecido en el Estado de las autonomías, no pueden en ningún caso corresponderse apriorísticamente con un lugar determinado del espectro político.

\section{UN PRESUPUESTO INELUDIBLE. LOS TÉRMINOS DEL DEBATE SOBRE LA ORGANIZACIÓN TERRITORIAL EN EL PROCESO CONSTITUYENTE.}

\section{II.1. El NACIONALISMO COMO PREMISA}

No eran años sencillos aquellos que fueron testigos del proceso constituyente que alumbró el texto todavía hoy vigente ${ }^{3}$. La transición de un régimen autoritario a uno democrático debía hacerse en un contexto de fuerte crisis económica y desgraciada actividad terrorista. Las cuestiones a definir por el nuevo texto constitucional eran todas las exigidas por un Estado moderno, algunas de ellas enquistadas profundamente en nuestra historia y ligadas a sucesos dramáticos y no tan lejanos. Una de ellas, nadie lo dudaba, era la controversia sobre la forma de organización territorial del poder. Si bien puede decirse que se trataba de un debate de raíces históricas, el centralismo y la represión franquista habían acentuado las tensiones. Además, como efecto colateral, acercaron a formaciones políticas de izquierda tradicionalmente alejadas de cualquier nacionalismo a posiciones cercanas de éste. Así, en la agenda de numerosas formaciones, no sólo nacionalistas, la reorganización territorial del poder era un objetivo primario.

No es posible detenerse en el análisis de los antecedentes históricos ${ }^{4}$. Es suficiente recordar el peso de este debate en la última historia de España y,

3 Para una visión rica y diferente de aquellos años, sigue siendo ineludible, L. MARTÍN-RETORTILLO BÁQUER, Materiales para una Constitución. Los trabajos de un profesor en la Comisión Constitucional del Senado, Akal, 1984.

4 Para los antecedentes históricos del Estado autonómico, véase S. MUÑOZ MACHADO, Derecho público de las Comunidades Autónomas, Iustel, 2007, vol. I, págs. 87-106. 
particularmente, los avatares constitucionales en relación con el mismo durante la Segunda República. Precisamente, el Estado regional alumbrado por la Constitución de 1931 no sólo fue una de las primeras fuentes de inspiración del constituyente de 1978. Además, éste decidió que la experiencia autonómica de aquellos años sería presupuesto del devenir, al menos en sus inicios, de los distintos territorios del Estado. La consecuencia fue que las tres Comunidades Autónomas que habían aprobado Estatuto de Autonomía antes del fin de la guerra civil fueron beneficiadas no sólo con un acceso más rápido a la autonomía, sino también con una mayor definición constitucional, hasta el punto de que bien podía hacerse una lectura de aquellas como nacionalidades frente a las restantes regiones que no llegarían a alcanzar una verdadera autonomía política 5 .

Esta solución, ingeniosa y que tenía el mérito principal de facilitar un encuentro con las formaciones políticas nacionalistas más activas, guardaba en su interior el peligro de introducir en el presente constitucional del País, la semilla de un historicismo difícilmente conciliable con debates en términos de modernidad. Por otra parte, la solución en si mismo considerada distaba de ser inobjetable, incluso en términos puramente históricos. De los Estatutos citados sólo el de Cataluña llegó a estar realmente en vigor y no eran pocos los territorios que tenían avanzados, incluso muy avanzados, los trabajos de redacción del mismo. Lo cierto es que una consecuencia inevitable fue la de tildar a unas Comunidades con el adjetivo de históricas mientras que de las restantes parecía presumirse su ahistoricidad y marginalidad en relación con cualquier sentimiento de reivindicación nacionalista o simplemente de voluntad de autogobierno. Inevitablemente, la dialéctica de la simetría y de la emulación se abría y, además, desde una ventana abierta al agravio.

Ahora bien, justo es señalar que el problema de la organización territorial desde la identidad y el nacionalismo político se circunscribía en sentido estricto a dos territorios, Cataluña y País Vasco. No puede decirse objetivamente que en Galicia se diesen circunstancias similares. De lo señalado, aun en su esquematismo, puede deducirse una de las características más dañinas para la subsiguiente evolución del Estado. El problema político representado por estas dos Comunidades Autónomas no llega a mirarse cara a cara y se busca cubrir con un velo de generalidad más o menos intenso, sin dejar de crear, simultáneamente, sensaciones de agravio en el otro lado. Por otra parte, no puede olvidarse, el debate constitucional sobre este extremo era necesariamente deudor de su tiempo. De las ventajas del mismo pero también de sus limitaciones. Así, era inevitable que los horizontes de los legisladores en esta materia fuesen limitados, siendo la frontera del Estado regional un límite de difícil superación. Por otro lado, tampoco conviene olvidarlo, las dudas e

5 En un reciente artículo, Santos Juliá recuerda las raíces ideológicas del modelo republicano y el valor dado, especialmente desde Cataluña a la voz nacionalidad y a su inclusión en la Constitución (S. JULIÁ, Cataluña /España, El País, 13 de septiembre 2009). 
incertidumbres afectaban a todos los agentes que, a su vez, tenían abiertos casi todos los frentes que se pueden tener ${ }^{6}$.

La síntesis de estas circunstancias difícilmente podía ser en el mejor de los casos otra que la que fue. Un acuerdo de mínimos, afirmando principios esenciales y abriendo la posibilidad a un desarrollo dinámico de la descentralización, si bien, no cabe hoy olvidarlo, dentro de unos límites fijados por el propio texto constitucional. La necesidad y la voluntad de consenso dominante facilitaron un acuerdo esencial y casi unánime tanto en relación con el contenido de los correspondientes preceptos del texto constitucional como en los primeros años de su desarrollo.

\section{II.2. LA RESPUESTA CONSTITUCIONAL}

Sería absurdo, además de pretencioso, siquiera resumir en estas páginas la respuesta que el constituyente dio al desafío que representaba el problema, porque problema era, de la organización territorial en España. Pero desde las premisas señaladas y aun de forma incompleta y no excesivamente rigurosa, sí es conveniente repasar algunas de esas respuestas ya que resultan altamente indicativas bien para entender la posterior evolución del modelo bien para poder enjuiciarlo en toda su dimensión.

Como se señaló, se sabía más lo que no se quería que lo que se quería. Era inevitable, pues, lo que Blanco Valdés ha denominado la búsqueda de un compromiso apócrifo ${ }^{7}$. Basta una lectura distante del Título VIII de la Constitución para certificar esta afirmación. Desde su propio enunciado ("De la organización territorial del Estado") hasta la abundancia de disposiciones meramente transitorias, casi todo reflejaba un acuerdo en fijar los grandes principios, y ni siquiera todos, y procedimientos, y dejar todo lo demás después. Un después que debe ser inmediatamente aclarado, ya que en este caso la remisión no se limitaba al tiempo sino también a una norma diversa, el Estatuto de Autonomía, a la que se le cargaba de potencia, como el tiempo ha demostrado sobradamente. Así, el principio dispositivo se convertía en estructural para el desarrollo del modelo territorial.

Una expresión singular de la visión que el constituyente tenía sobre la cuestión que se examina es la posición que otorgó a la provincia en el texto constitucional. Posición naturalmente ligada a la rúbrica mencionada de la organización territorial del Estado. El texto constitucional aborda conjunta-

6 Estas limitaciones que uno u otro tipo son inherentes no sólo a cualquier proceso constituyente sino al más pequeño de los procesos políticos no pueden servir de premisa para una descalificación global de ese proceso como parece inferirse de algunas de las interpretaciones que en la actualidad postulan la superioridad del presunto pacto que respalda el Estatuto de Autonomía de Cataluña frente a su encaje o no en el ordenamiento constitucional. (así, J. RAMONEDA, La penúltima oportunidad, El País, 7 de septiembre, pág. 25).

7 Vid, R. BLANCO VALDÉS, El largo viaje de España: de la invención del Estado autonómico al impulso hacia la confederación, www.fundacionmgimenezabad.es, 2009, pág.2. 
mente régimen local y descentralización política. La provincia se constitucionaliza sin que pueda llegar a pensarse en su relación con las futuras Comunidades Autónomas. El devenir situará a esta entidad local, al menos en algunas Comunidades Autónomas, en una inevitable situación de tensión. Tensión que es buen reflejo de algunas características fundamentales de la evolución del Estado autonómico ${ }^{8}$.

Desde luego, no fue la potencia que se adjudicó a la provincia la única muestra de duda, incluso de desconocimiento, que refleja el texto constitucional sobre la forma de la descentralización política en España. La propia definición del Estado es una buena muestra de ello. La literalidad del artículo segundo de la Constitución muestra más indefinición que certidumbre? ${ }^{9}$ No es la menor expresión de ello la inclusión de la voz nacionalidad al lado de la de región. Indefinición acrecentada, no puede olvidarse, por el hecho de que el texto constitucional renunciaba a definir qué territorios eran región y cuáles nacionalidad. En realidad, por no hacerse, ni siquiera se definían estos términos adjuntando a los mismos las necesarias consecuencias.

Para un lector interesado no habría duda de que detrás de la referencia a ambos términos se encontraba una de las cuestiones fundamentales del diseño del nuevo Estado. Parecía lógico apuntar a que en el desarrollo del mismo se constituirían entidades políticas con un nivel de autonomía diverso. Como reiteradamente se ha señalado, otros preceptos constitucionales vendrían a abundar esta tesis. Si bien puede coincidirse fácilmente con esta presunción, no puede obviarse otro dato fundamental. Como se indicó, la Constitución no definía a los distintos territorios del Estado. De esta forma, con igual lógica podía pensarse que la consideración de un territorio como nacionalidad o región se dejaba a la voluntad del mismo. Dos argumentos, entre otros, apoyan esta idea. Por una parte, la propia lógica democrática. No habiéndolo tasado la Constitución ni establecido parámetro alguno, lo coherente sería pensar que acceder a uno u otro nivel de autonomía, definirse de una u otra manera, sólo podía depender de la voluntad última de los ciudadanos de cada territorio. El segundo argumento se encuentra inevitablemente vinculado al primero y a la propia lógica de predicar distintos niveles de autonomía, diferente posición en el conjunto del Estado autonómico a las nacionalidades de las regiones. Si esto era así, resultaba difícil cercenar de antemano la voluntad ciudadana limitando a unos territorios a unos ámbitos de autonomía mientras que a otros se les elevaba a cumbres más altas.

Sí, parece coherente entender que el constituyente quiso referirse a dos realidades diferentes con los términos antedichos. Pero inmediatamente ha de

$8 \mathrm{Al}$ respecto puede verse, T. FONT I LLOVET, F. VELASCO CABALLERO, L. ORTEGA ÁLVAREZ, El régimen local en la reforma de los Estatutos de Autonomía, CEPC, 2006; L. PAREJO ALFONSO, La reforma estatutaria y organización territorial del Estado en L. ORTEGA ÁLVAREZ (dir.), La reforma del Estado autonómico, 2005, págs. 245-264.

9 Para un reciente y excelente comentario de este precepto, J.J. SOLOZÁBAL ECHAVARRÍA, "Comentario al artículo 2. " en M.E CASAS BAAMONDE; M. RODRÍGUEZ-PIÑERO Y BRAVOFERRER, Comentarios a la Constitución española, Fundación Wolters Kluver, 2008 
señalarse que un mínimo de coherencia hermenéutica exige entender que no se predeterminaba la consideración de los distintos territorios, por otra parte, políticamente inexistentes en aquél entonces. Al igual que otras muchas cosas, ello se dejaba para el propio evolucionar del Estado. No creo que las diferencias procedimentales establecidas por el constituyente tuviesen fuerza para realizar esa adscripción previa. Cuestión diferente sería entender que la referencia a los Estatutos republicanos se complementaba con la posibilidad de acceso a la autonomía por el procedimiento previsto en el artículo 151 de la Constitución. Aun no eliminando todos los reparos, lo cierto es que esta opción eliminaría las objeciones más notables desde la lógica democrática. La Constitución entendería como nacionalidad, y, por tanto, con unas competencias y características institucionales determinadas, a los territorios que en el pasado expresaron esta voluntad y a aquellos que en el futuro lo hiciesen siguiendo esa vía.

Desde luego, no es posible concluir que ello es lo que quiso el constituyente. No lo es porque no se afirma expresamente. También es cierto que es posible oponer objeciones notables a ese modelo. El privilegio historicista, de débil apoyatura como hubo ocasión de indicar, y las especiales dificultades del procedimiento previsto en el artículo 151, no serían las menores. Pero creo que puede presumirse que ese fue el espíritu del constituyente. Hoy resulta difícil enjuiciar aquellos años desde la distancia. Sí es posible recordar algunas cuestiones que no dejan de ser importantes. Por ejemplo, que la conciencia de entidad territorial con dimensión política diferenciada no era la misma en todos los territorios que devendrían Comunidades Autónomas. O que, por seguir con ese argumento, que no era posible reducir a dos grados esa conciencia. España, como hoy, era bastante más diversa.

Resulta difícil cualquier ejercicio de juicio retrospectivo pero, y perdónese este excurso casi conclusivo, es inevitable que asome la idea de que una mayor claridad en el deseo político y, sobre todo, un mayor oír a los ciudadanos de las diferentes Comunidades Autónomas, habría podido producir una evolución más racional del modelo. Asimétrico, sí, en sus autonomías pero más coherente con las distintas sensibilidades ciudadanas y más coherentemente ordenada desde el Estado.

Ahora bien, tal y cómo ha subrayado la doctrina, ambigüedad, indeterminación, sí, pero también afirmación de principios estructurales y procedimentales ${ }^{10}$. Unidad, autonomía, solidaridad, procedimiento, jerarquía normativa, serían sólo alguna de estas ideas esenciales que siempre debieran tenerse presentes en el desarrollo del modelo constituyente. Y, junto a ello, algunas determinaciones concretas no menos importantes. Entre las mismas, y además de algunas referencias institucionales de indudable valor, no puede

10 En este sentido, entre otros, R. BLANCO VALDÉS, El largo viaje de España: de la invención del Estado autonómico al impulso hacia la confederación, ob. cit., pág.2; J. CORCUERA ATIENZA, Las reformas del modelo territorial en Alemania y España: dos lógicas diferentes en La reforma del Estado autonómico eespañol y del Estado Federal alemán, Fundación Manuel Giménez Abad-CEPC, 2009, págs. 61-62; F. DE CARRERAS SERRA, La reforma territorial: el cierre del modelo en La reforma del Estado autonómico..., ob. cit., pág. 99. 
dejar de destacarse las referencias al orden competencial contenidas en el texto constitucional.

Este punto merece una reflexión añadida. Como se ha reiterado, bajo la imagen de un modelo de doble lista, se esconde un modelo de lista única que sirve para fijar un núcleo irreductible de competencias del Estado. Es importante subrayarlo. Ese es el valor de este artículo, más allá de la interpretación que pueda darse a cada uno de sus parágrafos. Hay una consideración ideológica en su interior que no puede obviarse. El artículo condensa en sí mismo la dialéctica territorial del Estado ${ }^{11}$. Lo hace, además, en la doble perspectiva de los principios y de sus pronunciamientos concretos. Procuro explicarme. En su literalidad, el listado de este precepto traduce la unidad de la Nación española proclamada en el artículo $2 .^{\circ}$ del texto constitucional. En su omisión, debidamente complementada con la remisión a los Estatutos de Autonomía, el principio de autonomía. El largo y denso listado de competencias y materias sería la traducción de esa idea de unidad. Una idea, tampoco puede olvidarse, necesariamente vinculada a un por implícito no menos transcendente principio constitucional. Me refiero, claro está, al de igualdad de los españoles. Es decir, mediante ese listado y muy significativamente a través de la idea de legislación básica, el constituyente estaría estableciendo un principio de igualdad u homogeneidad mínima que, simultáneamente, estaría delimitando el espacio propicio a la diversidad.

No es pues escaso tampoco lo que contiene la Constitución en el orden de lo concreto. Abundaría en esta idea el análisis singular de ese listado, destacando el valor simbólico e ideológico de algunas de las materias allí contenidas. Podría referirme a la reserva de funciones connaturales a la forma política de Estado. Pero prefiero condensar el reflejo de esta idea en la posición y significado de su parágrafo primero. Aun no viendo en él un principio-instrumento de homogenización global atribuido al Estado, es imposible no ver en el mismo una afirmación ideológica ligada al significado global del artículo 149.1. La inclusión de los derechos y deberes constitucionales y su posición en cabeza del largo listado hacen difícil extraer otra conclusión ${ }^{12}$.

Adelantando alguna idea, se puede compartir que, necesariamente, el listado de competencias ofrece un margen interpretativo y que, por tanto, se abre a la dialéctica unidad/autonomía que encierra todo Estado políticamente descentralizado. Ello no sólo resulta inevitable sino necesario. El tiempo modula las palabras. También las propias circunstancias políticas y será pre-

11 Por ello, es normal que la doctrina haya prestado especial atención a la nueva técnica competencial incorporada a los Estatutos desde el texto catalán y que para una parte de ella se encuentre en la misma el verdadero núcleo de la reinterpretación del Estado que los nuevos Estatutos supondrían (L. ORTEGA ÁLVAREZ, La redefinición por los Estatutos de Autonomía de la distribución territorial del poder contemplado en la Constitución en La reforma del Estado autonómico, ob. cit., págs. 16-18; P. BIGLINO CAMPOS, Reforma de la Constitución, reforma de los Estatutos de Autonomía y configuración constitucional del orden de competencias, RCG n. ${ }^{\circ}$ 65, págs. 7-30).

12 En este sentido, J. TUDELA ARANDA, Derechos constitucionales y autonomía politica, Cívitas-IVAP, 1994, 471 págs. 
ciso ordenar conforme a las mismas aquello que se escribió en un tiempo necesariamente diferente. Ahora bien, lo que no se podrá es desnudar de su significado esencial ese núcleo competencial.

Las presencias deben ser completadas con una somera referencia a las ausencias. El desarrollo del modelo de Estado no se entiende sólo desde lo que afirma la Constitución o desde aquello que permite desde su ambigüedad. También se entiende por sus carencias. Unas carencias inevitablemente vinculadas a las dudas que dominaron aquél proceso. En absoluto puede entenderse como casual la débil o inexistente presencia del principio de colaboración o el propio diseño del Senado ${ }^{13}$. Por el contrario, el diseño de esta Cámara no será sino coherente con un modelo de organización territorial del Estado en el que la provincia sigue siendo una realidad potente y, sobre todo, valga la redundancia, real, frente a otro, la Comunidad Autónoma, que no es sino abstracción indeterminada más allá de lo que comenzaban a dejar vislumbrar los entes preautonómicos. Será importante retener que no es precisamente una visión de radical descentralización la que impulsa esas y otras omisiones. Más bien su origen trae causa de la falta de conciencia por parte de los constituyentes no ya de cuál sería, sino de cuál debía ser el nivel de descentralización que se alcanzaría con el texto constitucional.

Es un dato a no obviar. Creo que puede afirmarse que los niveles de descentralización alcanzados en España incluso con el desarrollo de los Estatutos de Autonomía de primera generación es superior a lo imaginado por aquellos que elaboraron la Constitución. Creo también que ello puede considerarse normal. Pasados unos años y, con ellos, orilladas algunas de las limitaciones más significativas presentes en 1978, era natural pensar en una evolución dinámica y en clave descentralizadora del modelo diseñado por el constituyente. Ahora bien, debe tenerse conciencia de ello. Al menos para relativizar los enjuiciamientos negativos que al respecto se realizan en ocasiones. Desde luego, es posible estimar que ese desarrollo era insuficiente, como se ha hecho al plantear la aprobación de los Estatutos de segunda generación. Pero creo que el fundamento de ese planteamiento difícilmente puede radicar en un enjuiciamiento negativo de la interpretación que por todos los agentes implicados se dio al principio constitucional de autonomía política.

\section{II.3. La primera generación de Estatutos de Autonomía}

Cuando el Estado autonómico ha abierto una nueva etapa ligada a la aprobación de nuevos Estatutos de Autonomía, parece obligado volver la mirada a un territorio que es cruce del ayer y del hoy. Del ayer, porque seis

13 Ambas cuestiones han sido objeto de un extenso tratamiento por la doctrina. Por todos, véanse: M.J. GARCÍA MORALES, Las relaciones intergubernamentales en el Estado autonómico: estado de la cuestión y problemas pendientes en el vol. col. Las relaciones intergubernamentales en el Estado autonómico, CEPC, 2006, págs. 9-72; J. SOLOZABAL ECHAVARRÍA (Ed.), Repensar el Senado. Estudios sobre su reforma, Servicio de publicaciones del Senado, 2008. 
de los textos que pertenecieron a esa primera generación son ya pasado. Del presente, porque, por el contrario, otros once permanecen en vigor. Precisamente, ésta es una de las características más notables del actual estado de cosas. La convivencia jurídica de tiempos y fondos bien diferentes del Estado autonómico. Convivencia que, por otra parte, se desconoce si ha llegado para quedarse o, por el contrario, en un tiempo indeterminado, finalizará con la aprobación de nuevos Estatutos por las restantes Comunidades Autónomas.

La mirada a los Estatutos de primera generación obliga a recordar las diferencias entre los mismos en función del procedimiento de acceso. El tiempo apremiaba. Como se indicó, la apuesta por la descentralización política contenida en la Constitución era, ante todo, la respuesta del constituyente a las demandas planteadas por el nacionalismo vasco y catalán. La consecuencia no pudo ser otra que la rápida aprobación de los Estatutos para estas Comunidades. Hoy es importante recordar que ambos textos recibieron no sólo el refrendo mayoritario de los ciudadanos de sus respectivas Comunidades sino también los parabienes generalizados de las formaciones políticas, incluidas las nacionalistas. Los reparos formulados por el Partido Nacionalista Vasco se subsumieron pronto en la retórica en la medida que desde el Gobierno de la Comunidad Autónoma se pudo apreciar el potencial del nuevo texto.

La tercera Comunidad Autónoma afectada por la opción constitucional de rápido acceso a la autonomía era Galicia. El proceso se repitió y la Comunidad Autónoma se dotó asimismo de un texto equiparable al de las otras dos Comunidades Autónomas. Sin embargo, hubo diferencias. No es la menor el diferente compromiso de la ciudadanía gallega, reflejado en la baja participación con la que se aprobó el Estatuto ${ }^{14}$. Por otra parte, el menor perfil nacionalista de esta Comunidad se tradujo en otro dato de la mayor significación. Si en Cataluña y en el País Vasco el Gobierno fue asumido por partidos de sesgo nacionalista, no sucedió lo mismo en Galicia. El dato es importante porque no puede entenderse la evolución del Estado autonómico sin retener el ejercicio del gobierno por formaciones nacionalistas en País Vasco y Cataluña hasta fechas muy recientes.

La aprobación del Estatuto de Autonomía del País Vasco debería analizarse conjuntamente con la aprobación de la Ley Orgánica del Amejoramiento del Fuero Navarro. Si bien su iter constitucional es bien diferente, como es conocido por todos, ambos textos coinciden en una circunstancia que es forzoso traer a colación en este momento ya que es fundamental para entender la evolución del Estado autonómico. Como es lógico, me refiero a la inclusión en ambos textos de los llamados derechos históricos y que pronto

14 El Estatuto de Autonomía de Galicia se aprobó con una participación del 28,27 \%, de los que el 73, 35\% fueron votos positivos. La participación en el referéndum del Estatuto de Autonomía del País Vasco fue del 59,77 \% con un voto favorable del 90,29 \% y del catalán del 59,70 con un $80,15 \%$ de voto a favor. La participación más alta se registro en Andalucía con un 64,19 y un voto a favor del 86,94 . 
sirvieron para fundamentar un régimen fiscal radicalmente diferente al vigente en el resto del País ${ }^{15}$. Un hecho que, entre otras cosas, habría de traducirse en una significativa mayor capacidad financiera de estos territorios. No es posible ahondar en este tema, pero para la intención de estas páginas es necesario consignar como la deriva de ese presupuesto constitucional y estatuyente, acabará provocando una sensación de agravio que, inevitablemente, habría de dejar el terreno del lamento para adoptar la cara de la reivindicación enérgica.

Nace así una diferencia que no tardaría en ser apreciada por muchos como un privilegio. Privilegio de difícil justificación material y que, como se dijo, forzosamente habría de ser una herida abierta. Hoy, cuando se repara y se echan en cara determinadas diferencias, no se repara suficientemente en el lastre que para un diseño racional del Estado supone conllevar dos sistemas tributarios y de financiación territorial. Además, como es notorio, no se trata de una herida abierta por el constituyente. Si bien es cierto que éste da fundamento constitucional a esos derechos históricos, es lo cierto que su desarrollo podría haber sido otro, especialmente en lo tocante al cálculo de las cifras del denominado modelo de concierto. Un cálculo más paritario que hubiese equiparado los ingresos de esas Comunidades con los las restantes habría dejado el tema en el terreno del reconocimiento y habría alejado los fantasmas del privilegio y, con él, de la injusticia ${ }^{16}$.

Como es sabido, esta parte de la primera etapa del Estado autonómico se cierra necesariamente con la denominada rebelión de Andalucía que llevó a esta Comunidad Autónoma a provocar el referéndum previsto en el artículo 151 como paso previo para el acceso a la entonces denominada "autonomía plena ${ }^{17}$. No fue Andalucía la única región que lo intentó e incluso que lo hizo con éxito. En otras, como es el caso de Aragón, también se lograron los apoyos requeridos para forzar esa vía. En este caso, sólo un repentino cambio de opinión de la Unión de Centro Democrático impidió que Andalucía no fuese sola al mismo ${ }^{18}$. El resultado fue que Andalucía se convertía en un protagonista inesperado en la escena autonómica. Un protagonista que no sólo representaba a su territorio sino que venía a personificar el surgimiento de una tendencia poderosa que habría de marcar la evolución y definición

15 Para un análisis de la relación entre estos derechos y la Constitución, J.J. SOLOZÁBAL ECHAVARRÍA, Constitución y derechos históricos en su volumen Nación y Constitución, Biblioteca Nueva, 2005, págs. 93-120.

16 Sobre la problemática general de los derechos históricos y la amplia bibliografía existente, puede verse J. TUDELA ARANDA, La disposición adicional primera de la Constitución y los nuevos Estatutos de Autonomía. La historia como legitimación de la autonomía, RAP n. ${ }^{173,} 2007$, págs. 143-281.

17 Juan Cano denomina gráficamente como "efecto Andalucía" las consecuencias de la "rebelión" andaluza (J. CANO BUESO, Una reflexión sobre el Estado autonómico www.fundacionmgimenezabad.es, 2009, pág. 6).

18 Sobre los avatares del proceso de creación de la Comunidad Autónoma aragonesa, C. GARRIDO LÓPEZ, Demanda regional y proceso autonómico: la formación de la Comunidad Autónoma de Aragón, Gobierno de Aragón, 1999. 
del Estado autonómico. El diseño del nuevo mapa territorial del Estado se escapa a los partidos políticos. La voz autonomía se había hecho demasiado fuerte como para que fuese posible reservarla sólo para unos determinados territorios.

La consecuencia no se hizo esperar y gráficamente se expresó en la célebre frase de "café para todos". La dialéctica entre homogeneidad y heterogeneidad ya presente en la II República no había tardado en hacerse presente. Además, otros datos certificaban que la realidad territorial española no podía reducirse a un binomio nacionalista/no nacionalista. Sólo desde esa percepción se entienden los tempranos procesos de transferencia de competencias a Comunidades Autónomas como Canarias y Comunidad Valenciana, la opción foral de Navarra o el expreso y contundente rechazo que Aragón mostró a una autonomía que entendía disminuida. Para cualquier espectador atento, era visible que tres Españas se dibujaban desde la percepción del hecho autonómico. Por una parte, la que representaba la demanda nacionalista, esto es País Vasco y Cataluña. Por otra, aquellos territorios que dotados de una clara conciencia de identidad colectiva no albergaban de forma mayoritaria postulados nacionalistas. Es decir, Galicia, Navarra, Canarias, Comunidad Valenciana y Aragón. Finalmente, una serie de territorios que bien veían la autonomía desde una mayor ajenidad bien estaban incluso por afirmarse como espacio político común.

Esta heterogeneidad se tradujo en un mapa jurídico diverso que si bien no reflejaba exactamente la división señalada, lo cierto es que la corroboraba en sus líneas generales. Café para todos, sí, pero con matices. Ni la calidad, ni la cantidad, ni las tazas eran las mismas. Alguien podría decir, pues, que nada ha cambiado. Que hoy, como ayer, nuestro mapa territorial es heterogéneo. Ello sería cierto si se obvia el dato, fundamental por lo demás, de que por previsión constitucional, esa heterogeneidad estaba sumergida en la transitoriedad. Es cierto que hubiese podido confirmarse. Pero también lo es que era más fácil, como finalmente sucedió, que abriese las puertas a un camino cuya meta era la igualación.

Son diversas las ideas que podrían desarrollarse a partir de este punto. Premisas sin las cuales no es posible entender cabalmente el desarrollo territorial del Estado. Podría desarrollarse el modo en el que la semilla de la tensión simetría/asimetría ocupa su lugar. Pero creo más significativo subrayar como los inicios del Estado autonómico descansan sobre una premisa peligrosa: la aceptación, con su correspondiente reflejo jurídico, de la singularidad de las Comunidades Autónomas nacionalistas sin la existencia de un reconocimiento político, explícito y comúnmente aceptado de la misma. Necesariamente, desde esa premisa, se habría de hacer frente a una tensión continua llena de vaguedades, cuando no de ocultamientos.

En cualquier caso, no puede desconocerse que, en todos los supuestos, los Estatutos aprobados facilitaron la consolidación de nuevas e importantes estructuras administrativas. Unas estructuras que poco a poco se fueron haciendo reconocibles por los ciudadanos y que, simultáneamente, sirvieron 
para el nacimiento y paulatina consolidación de nuevas élites políticas que irían, entre otras cosas, adquiriendo perfil y personalidad propias en el interior de los respectivos partidos políticos. Tampoco que ello se realizó de forma paralela a la consolidación y progreso del Estado social en un marco general de crecimiento económico y del nivel de vida de los ciudadanos. Y todo ello en un muy reducido espacio temporal. Con esas premisas resulta difícil negar que el desarrollo del principio autonómico fué un éxito, aunque en las mismas puedan encontrarse semillas de algunos de los problemas que hoy protagonizan el debate político ${ }^{19}$.

Finalmente, es preciso indicar que la aprobación de esos primeros Estatutos y la puesta en marcha de las correspondientes estructuras administrativas y políticas se completó con la extraordinaria labor del Tribunal Constitucional y de una parte significativa de nuestra doctrina. Una visión proclive al desarrollo autonómico, hoy hay que recordarlo, cuando algunos de los que entonces tenían visiones más avanzadas de las posibilidades de descentralización que escondía la Constitución son tenidos por peligrosos centralistas, que favoreció no sólo una rapidez del proceso de descentralización sin parangón en el derecho comparado, sino también notables dosis de calidad en esa autonomía. Recordar hoy la Sentencia frente a Ley Orgánica de Armonización del Proceso Autonómico (y otras) es más que necesario. No sólo por el contenido de la misma sino por lo que ello suponía de rechazo a una visión determinada del Estado consensuada mayoritariamente por los partidos de ámbito estatal.

\section{DIALÉCTICAS Y EVOLUCIÓN EN EL ESTADO AUTONÓMICO HASTA EL AÑO 2000}

\section{III.1. LA CONSOLIDACIÓN DE LA DIALÉCTICA UNIDAD/AUTONOMÍA}

Vagamente desarrollada en el texto constitucional, pronto se pudo percibir que uno de los motores del Estado resultante iba a ser el de la dialéctica unidad/autonomía ${ }^{20}$. Dialéctica poderosa e inherente a cualquier Estado descentralizado. La peculiaridad del Estado español venía dada desde una perspectiva sustantiva por la indefinición relativa de los límites de esa autonomía y por las propias incertidumbres y dudas de sus actores. Desde un punto de vista estrictamente jurídico, la singularidad la aportaba una norma que como el Estatuto de Autonomía estaba llamada a definir el marco autonómico da cada Comunidad Autónoma con la enrevesada y, a la postre, poco afortunada

19 Una valoración positiva del proceso autonómico: J. PEMÁN GAVÍN, El sistema español de autonomias territoriales. Apuntes para un diagnóstico, ob. cit., págs. 2-5; J.J. SOLOZÁBAL ECHAVARRÍA, Falsas y verdaderas reformas del Estado autonómico en su volumen Tiempo de reformas. El Estado autonómico en cuestión, Biblioteca Nueva, 2006, págs. 28-32.

20 Vid. S. MUÑOZ MACHADO, Derecho público de las Comunidades Autónomas, ob. cit, vol. I, págs. 196-309. 
fórmula de doble aprobación por la Cámara autonómica y las Cortes Generales, cuando no con el añadido del refrendo.

Como se indicó, no es que la Constitución callase al respecto. En particular, el artículo 149.1 definía con cierto detalle el núcleo material de la unidad del Estado. Otros preceptos, como el 139.1 establecían premisas ideológicas insoslayables. Sin embargo, desde la aprobación de los Estatutos de primera generación pudo percibirse la existencia de un amplio campo de indefinición. La ambigüedad de algunas voces se reforzó conscientemente con técnicas como la llamada estatutaria a una exclusividad "sin perjuicio". Puede decirse que de esta manera se seguían desdibujando las consecuencias nítidas de la dialéctica que se explica. Porque si bien es cierto que no parece realista exigir una claridad contundente en cuestiones necesariamente vaporosas, también lo es que no parece posible negar que en ningún caso los diferentes agentes políticos hicieron una apuesta por la claridad prefiriendo que la tarea precisa fuese realizada por el Tribunal Constitucional que, con paciencia y rigor encomiable, acabó definiendo los rasgos esenciales del sistema.

De manera consciente se ha hecho omisión del significado de la legislación básica para la dialéctica que se plantea. Si el conjunto del artículo 149.1 encierra el ser constitucional de la misma, el instrumento de la legislación básica va a condensar la reserva que de la definición de esa dialéctica se atribuye al legislador ordinario. No otra cosa significará definir aquello que es básico. Es básico para un legislador determinado aquello que debe ser igual para todos los españoles. Una determinación que por imperativo democrático puede variar en el tiempo siempre dentro de la delimitación previa realizada por el constituyente. Así, dentro de esos límites, serán constitucionalmente posibles visiones diversas del alcance material de la unidad. Por la profusión e importancia de las materias afectadas, la legislación básica se convirtió en un campo natural de disputa con inevitable fin, en muchas ocasiones, en el Tribunal Constitucional. Como dato añadido, puede aludirse a como, con independencia del partido político gobernante en el Estado, la circunstancia decisiva a la hora de la definición de lo básico va a ser la existencia o no de una mayoría nacionalista en las Cortes Generales, de forma coherente con el principio democrático.

Se podría hacer mención a otras significativas variables que incidieron e inciden en esta dialéctica. De todas ellas, creo que merece subrayarse el paulatino y afortunado desarrollo del Estado social. En paralelo a la construcción del Estado autonómico, y una vez satisfecha la institucionalidad mínima, existían otros e importantes retos que atender. No era el menor el llevar a cabo un desarrollo eficaz del modelo de Estado social previsto por el constituyente. Una tarea de la que difícilmente podía hacer dejación el Gobierno del Estado, aunque para su ejecución en numerosas ocasiones tuviese que adentrarse en las lindes de las competencias autonómicas o retrasar la asunción de algunas de ellas. Así, ese esfuerzo necesariamente ligado a la unidad de la Nación habría de influir en los tiempos y en una primera definición del modelo territorial del Poder. Una vez levantadas las estructuras propias de ese 
Estado sería posible realizar una visión del mismo desde la autonomía, como a la postre ha sucedido.

La referencia al Estado social cobra hoy especial significación porque se encuentra directamente vinculada a una nueva dialéctica, la relación entre igualdad y desigualdad inherente a un Estado descentralizado y que con motivo de la aprobación de los nuevos Estatutos de Autonomía se ha incorporado a la agenda de nuestro modelo territorial. Con los nuevos textos estatutarios y, singularmente, con la inclusión de cartas de derechos y libertades en los mismos ha irrumpido en la agenda del debate político y académico las tensiones derivadas del posible reconocimiento heterogéneo de derechos. En realidad, no era necesaria la reforma estatutaria para que este debate se hubiese podido suscitar. Pero, como en tantas otras cosas, ha sido la aprobación de los nuevos textos el elemento catalizador de la misma ${ }^{21}$.

\section{III.2. LA INEVITABLE DIALÉCTICA UNIFORMIDAD/HETEROGENEIDAD}

Aunque ya habido ocasión y necesidad de referirse a la dialéctica planteada por las tensiones derivadas de las preferencias entre un modelo de Estado simétrico en lo territorial frente a quienes postulan un modelo asimétrico, es preciso detenerse siquiera brevemente en la misma, ya que se trata de uno de los nervios que ilustran la evolución de todo el modelo ${ }^{22}$.

Como es conocido, no se trata de un debate nuevo. El Estado regional de la II República fue testigo de un debate que transcendió el escenario político para provocar un hondo e interesante debate intelectual entre Azaña y Ortega $^{23}$. Por otro lado, tampoco se trata de un debate genuinamente español. En otros Estados descentralizados también es posible encontrar esta tensión. Si bien el federalismo genéricamente es proclive a una visión homogénea de la posición que en el Estado les cabrá ocupar a las entidades subestatales, lo cierto es que también existen ejemplos significativos de lo contrario $^{24}$. Al margen de la utilidad de posibles análisis comparatistas, es

21 Visiones diferentes de la influencia de la segunda generación de Estatutos y de su influencia sobre la igualdad en: J. PEMÁN GAVÍN, El sistema español de autonomías territoriales..., ob. cit., págs. 13-20; J. CANO BUESO, Una reflexión sobre el Estado autonómico, págs. 26-30.

22 Como introducción a este debate puede verse el sugerente trabajo de R. BLANCO VALDÉS, Nacionalidades históricas y regiones sin historia, Alianza, 2005, págs. 55-77.

23 Vid M. AZAÑA y J. ORTEGA Y GASSET, Dos visiones de España. Discursos en las Cortes constituyentes sobre el Estatuto de Autonomía de Cataluña, Círculo de Lectores, 2005. Sobre esta polémica, J.J. SOLOZABAL ECHAVARRÍA, Falsas y verdaderas reformas del Estado autonómico en su libro Tiempo de reformas. El Estado autonómico en cuestión, Biblioteca Nueva, 2006, págs. 31-32.

24 Para una completa visión comparatista del federalismo, R.L. WATTS, Sistemas federales comparados, Marcial Pons, 2006. Sobre los llamados hechos diferenciales y su incidencia en el modelo español, entre otros: J.F. LÓPEZ AGUILAR, Estado autonómico y hechos diferenciales, CEPC, 1998; E. AJA, El Estado autonómico. Federalismo y hechos diferenciales, ob. cit.; E. FOSSAS y F. REQUEJO (eds), Asimetría federal y Estado plurinacional. El debate sobre la acomodación de la diversidad en Bélgica, Canadá y España, Trotta, Madrid. 
importante retener la normalidad de estas tensiones. Tensiones inherentes a la diversidad propia de los Estados. En ocasiones se señala que los distintos territorios que integran España son muy diferentes entre sí, a modo de explicación de su presunta debilidad como Nación y Estado. Una lectura maliciosa que olvida que la diversidad es nota integrante de la mayoría de los Estados. Al igual que será natural que en un modelo descentralizado del poder surjan tensiones entre las diferentes partes.

En este punto sería necesario realizar un excursus detenido sobre lo que bien podría denominarse verdades y mentiras en la lectura nacionalista del mapa español. Verdades y mentiras porque de todo hay en el discurso que desde el inicio de la transición política española ha inspirado todo el modelo de organización territorial del poder. No es posible, de nuevo, realizar con la profundidad que merece este análisis. Pero aun a riesgo de pecar de ligereza y dejar demasiadas cosas sin desarrollar, parece preciso detenerse en lo que podría considerarse elementos estructurales de ese discurso. Por supuesto, no se pretende categorizar nada. Verdad y mentira no es sino la necesidad de un juego retórico para ilustrar mejor el debate que se desea plantear.

Entre aquello que cubre la mentira de ese discurso, no ocupa el menor lugar la alegación historicista como soporte de la autonomía política e, incluso, de eventuales aspiraciones secesionistas. Como se indicó, la Constitución abrió una puerta desgraciada a la historia. Una puerta que como entonces ya pareció inevitable a parte de nuestra mejor doctrina ${ }^{25}$, estaba destinada a abrirse paulatinamente llegándose mediante la misma a unas consecuencias difícilmente previstas por el constituyente. Si esas consecuencias estarían en la raíz del revival historicista presente en los Estatutos de segunda generación, los problemas relacionados con la alegación de la historia como explicación de una necesaria asimetría son previos a esos textos y se corresponden con la segunda vía abierta por el constituyente al río de la historia, la del acceso a la autonomía de acuerdo con la Disposición Transitoria Primera de la Constitución. Lejos de quedar como un ingenio político para favorecer un rápido acceso político a la autonomía en aquellos territorios donde la demanda política de autogobierno era mayor, esta fórmula sirvió como fundamento de un vaporoso estado de opinión en función del cual las Comunidades Autónomas que pudieron favorecerse de esta vía eran las nacionalidades a las que aludía el artículo primero de la Constitución. Su singularidad transcendería la derivada del procedimiento de acceso de a la autonomía para convertirse en el reconocimiento de un ser diferente fundamentado en una tradición histórica singular. Como era de esperar, este discurso provocó necesariamente sensación de agravio en otros territorios españoles no exentos, precisamente, de historia, incluso de historia "propia", al modo de la reivindicada por las Comunidades que habían accedido por el artículo 151 de la Constitución, especialmente Cataluña y País Vasco.

25 Vid M. GARCÍA PELAYO, El proyecto constitucional y los derechos históricos en Obras completas, CEC, 1991. 
No se trata de analizar la verdad o no de los argumentos históricos esgrimidos desde esas y otras Comunidades. Se trata de separar a la historia del orden jurídico contemporáneo. De dejar su discusión a los historiadores y buscar el fundamento tanto del orden común como de las propias singularidades en los principios propios del Estado democrático. Precisamente, como inmediatamente se indicará, una de las peores consecuencias de la insistencia en ese discurso historicista es que ha llegado a ocultar las diferencias políticas que desde una visión democrática del Estado sí es posible apreciar entre las diferentes Comunidades Autónomas de acuerdo con su voluntad de autogobierno.

Junto a la historia, es preciso hacer referencia a aquello que bien podría denominarse la mentira de la ignorancia. El desconocimiento de la realidad territorial española en su conjunto es una nota común y característica de todo el discurso nacionalista. Desde el mismo, la visión de España es uniformemente dialéctica. Por un lado, los territorios con identidad nacional y nítida conciencia política diferenciada de Cataluña y País Vasco, más, en función de las circunstancias y básicamente por mor de la lengua, Galicia. Por otro, el resto de los territorios españoles que uniformemente se identificarían con un posición "regional" dentro del Estado. Si bien puede alegarse que los representantes de las formaciones políticas de esas Comunidades han votado las sucesivas reformas estatutarias por las que no sólo se incrementaba el nivel de autogobierno de las restantes Comunidades Autónomas sino en las que también se las llegaba a identificar como nacionalidad, lo cierto es que el nervio de ese discurso sigue siendo esencialmente ajeno no sólo a la propia evolución habida en los distintos territorios (una consecuencia indiscutible del hecho autonómico ha sido el fortalecimiento de identidades políticas colectivas allí donde no existían), sino también a diferencias sustanciales entre esos territorios bien derivadas de circunstancias geográficas como es el caso de las Comunidades insulares, histórico-jurídicas como sería el caso de Navarra o el de aquellas que como Aragón, Andalucía o Comunidad Valenciana han reclamado de distinta manera su propio espacio por mor de diferentes circunstancias pero siempre con el sustrato común de una voluntad de autogobierno no inferior al de otras Comunidades Autónomas. Una mentira que, tampoco debe desconocerse, llega a la raíz cuando niega la virtualidad de España como Nación, alegando una debilidad histórica inherente a su origen. La negación de España como nación no por necesaria para buena parte del discurso nacionalista deja de ser preocupante para la construcción racional de un modelo de organización territorial que satisfaga a casi todos ${ }^{26}$.

Así, la voluntad de equiparación en el autogobierno ha sido un motor del desarrollo del Estado autonómico. Esas Comunidades que en estas páginas se denominan como la tercera España territorial, han sido, a su vez, im-

26 Para una aproximación objetiva y racional a los elementos que cohesionan España y que permiten reducir la grandilocuencia de la nación a lo concreto, J. PEMÁN GAVÍN, El sistema español de autonomías territoriales..., ob. cit., págs. 31-34. 
pulso para las restantes. Sin embargo, y así se entra en el territorio de las verdades del discurso nacionalista, lo cierto es que existen diferencias políticas objetivas entre la afirmación popular del autogobierno entre las dos Comunidades citadas del País Vasco y Cataluña y las demás, incluidas aquellas de esa tercera España que más activas han podido ser en la búsqueda de un modelo igualitario. Como se dijo, otras banderas han llegado a ocultar los perfiles propios que la voluntad de autogobierno tiene en esos territorios. Perfiles propios que estuvieron presentes en el debate constitucional y que son explicación no sólo de las singularidades iniciales sino, incluso, de la apuesta decidida por un modelo de descentralización política ${ }^{27}$.

Como se ha dicho, se trata de diferencias objetivas. Diferencias desde fundamentos democráticos sólo pueden buscarse en la conformación de los sistemas de partidos de ambas Comunidades y en los diferentes resultados electorales, incluyendo la posición de las formaciones políticas nacionalistas en las distintas Legislaturas de las Cortes Generales. El análisis de los mismos, como es conocido, confluye en un sencillo reconocimiento de una identificación con las posiciones más nítidamente nacionalistas no presente en otras Comunidades. En todo caso, conviene añadir que el mismo análisis sirve para certificar la existencia de esa tercera España territorial, ya que en otras Comunidades también existirán singularidades en su sistema de partidos e, incluso, en ocasiones, con reflejo en las Cortes Generales. Creo que es éste el dato que debería retenerse y el dato que podría servir para un planteamiento más racional de la dialéctica analizada. Es evidente que la opción por posiciones nacionalistas no puede traducirse de ninguna manera en una posición privilegiada para aquellos ciudadanos representados por las mismas. Pero, lejos de esta opción existen territorios que el derecho y la política podrían explorar para buscar soluciones equilibradas que armonizasen los diferentes intereses en juego. En todo caso, resulta necesario que este debate se realice de forma clara y no oculto por velos que sólo han extendido las sombras y las sospechas.

Ahora bien, no basta con mirar la cara de estos territorios. Es preciso también tomar en consideración la posición de las otras Comunidades Autónomas, algo que, como se ha señalado, en demasiadas ocasiones escapa al discurso nacionalista. Cierto o incierto, hoy se ha instalado en gran parte de los ciudadanos que no habitan esas Comunidades equívocamente llamadas históricas, una sensación de agravio. Creo que puede afirmarse que se encuentra bastante extendida la percepción de que la reclamación nacionalista se ha traducido en sustanciales ventajas materiales para los habitantes de esos territorios. Se trata de una sensación. Ni siquiera importa que las cifras lleguen a demostrar lo contrario. En todo caso, lo que parece innegable es que los pronunciamientos políticos de unos y otros, los propios argumentos es-

27 En este sentido, G. JAUREGUI, Las reformas del Estado autonómico español: un primer balance de urgencia en la reforma del Estado autonómico español..., ob. cit., págs. 92-93; E. AJA, El Estado autonómico. Federalismo y bechos diferenciales, Alianza, 2003, pág. 175. 
grimidos desde el nacionalismo, no han favorecido la posibilidad de corregir esta percepción. De esta manera, se ha llegado a la paradoja actual de que unos y otros se sientan discriminados y nadie contento, salvo, el silencio es la mejor confirmación, vascos y navarros. Algo se ha tenido que hacer mal políticamente cuando la sensación de agravio se extiende a todos los territorios.

La referencia al silencio de las Comunidades Vasca y Navarra debe servir para la aclaración de que si bien a efectos argumentativos se ha identificado los discursos nacionalistas de Cataluña y el País Vasco, lo cierto es que País Vasco y Navarra representan de por sí una asimetría fundacional peligrosamente profundizada con el desarrollo del modelo territorial. Así, puede decirse sin caer en el juego de palabras, que la posición del País Vasco es la búsqueda de asimetría política desde el reconocimiento previo de una fundamental asimetría financiera. Como ya hubo ocasión de indicar, asimetría financiera que, inevitablemente, se ha convertido en un muy importante lastre para un adecuado funcionamiento del modelo territorial.

El debate entre asimetría y simetría, homogeneidad y heterogeneidad, no sólo ha sido uno de los vectores ideológicos del desarrollo del Estado sino que se ha convertido, especialmente tras la aprobación de los nuevos Estatutos, en una de las claves para la comprensión del Estado en su conjunto. Como habrá de verse posteriormente, sin que parezca que haya existido una conciencia muy nítida al respecto, una de las consecuencias fundamentales de ese proceso de reforma ha sido la de certificar, al menos por un tiempo que no parece reducido, un modelo de Estado esencialmente asimétrico. En la práctica, de un modelo a la carta. Al margen de cualquier otra consideración, esa heterogeneidad, esa diversidad en la posición jurídica, e incluso política de las diferentes Comunidades Autónomas, va a interrogar abiertamente por la capacidad del Estado para gestionar la diversidad. La radicalización de la dialéctica simetría/asimetría va a provocar una necesaria pregunta por el grado de uniformidad exigido por un Estado para ser eficiente en el cumplimiento de su servicio a los ciudadanos.

\section{III.3. LOS ACTORES DEL PROCESO}

La voluntad, quizá errónea, de dejar apuntados los datos que se estiman más significativos del proceso analizado, aun en la conciencia de la imposibilidad de un análisis someramente riguroso, lleva en este momento a realizar una breve disquisición sobre su dimensión subjetiva. Algunos de los protagonistas, como los partidos políticos o el Tribunal Constitucional son bien conocidos y poco se puede añadir sobre su papel en el mismo. Como ya ha habido ocasión de señalar, la evolución del Estado autonómico resulta incomprensible si no se toma en consideración el protagonismo de estos dos actores. Para el objetivo de estas páginas, baste recordar en relación con los partidos políticos que las grandes líneas del proceso fueron determinadas en 
virtud de una doble tensión nacida del juego de esos partidos. Por una parte, del acuerdo entre los dos grandes partidos nacionales, Partido Socialista y Partido Popular, determinante para la concreción del primer diseño del Estado autonómico e, incluso, para un primer desarrollo de las denominadas Comunidades de vía lenta. Por otra, la derivada de la presión de los partidos nacionalistas, determinante cuando los partidos de ámbito nacional debieron acudir a los mismos para soportar el Gobierno de la Nación. Aunque no resulta posible extenderse en este punto, sí conviene realizar una llamada sobre el interés que poseería una investigación rigurosa de las contraprestaciones demandadas por estos partidos para ofrecer un apoyo esencial a la gobernabilidad del Estado. Abusando de la memoria, creo que puede afirmarse tanto un elogiable sentido de la gobernabilidad como un horizonte de reivindicación de autogobierno bastante alejado de los parámetros que hoy aparecen como irrenunciables.

Poco puede añadirse sobre la labor del Tribunal Constitucional en este punto que no haya sido reiteradamente escrito. La aportación de este órgano constitucional ha sido tan contundente que en buena medida es doctrina común que el modelo español de organización territorial es un modelo jurisprudencial. Una jurisprudencia, ello sí es importante subrayarlo, esencialmente proclive a una visión amplia de la autonomía contemplada en la Constitución tal y como lo atestiguaron sentencias fundamentales como la ya citada frente a la LOAPA, la interpretación de los principios de prevalencia y supletoriedad o la elaboración del concepto de legislación básica como un concepto material, impidiendo de esta manera que la mera inactividad legislativa del Estado bloquease la labor de los Parlamentos autonómicos. Ligada a la labor del Alto Tribunal, habría que mencionar el papel desarrollado por la doctrina. España ha desarrollado un amplio y valioso bagaje académico que no sólo ha resultado imprescindible para el desarrollo de nuestro modelo territorial sino que ha contribuido a enriquecer notablemente la doctrina internacional sobre descentralización política. Al igual que en el caso de la posición de los partidos nacionalistas, sería de interés un análisis de la evolución de esa doctrina. Creo que el resultado certificaría una paulatina flexibilización de las primeras interpretaciones de la Constitución, hasta el punto de que difícilmente puede encontrarse correspondencia entre los estudios realizados en la primera etapa del nuevo Estado y los que hoy pueden leerse.

El análisis de los actores necesarios para comprender nuestro modelo territorial y especialmente su evolución requeriría de otras paradas no menos importantes. Desde luego, no sería la menos relevante la que corresponde a la Unión Europea como un agente esencial para entender la entera evolución de nuestro Estado y, por supuesto, también de su modelo territorial. Si bien los constituyentes tenían clara su voluntad de incorporación a la entonces Comunidad Europea, lo cierto es que no podían alcanzar a conocer cuáles serían las consecuencias jurídico-políticas del ingreso. Mucho menos podían conocer cuál habría de ser la relación de poderes establecida entre el Estado descentralizado que intuían y esa adscripción que deseaban a una Europa 
que a su vez habría de recorrer un importante camino en paralelo a la consolidación y desarrollo de nuestro Estado descentralizado.

No muy diferente sería el análisis de la posición de otro sujeto necesario, los entes locales. Si, como se indicó, la Constitución da buenas muestras de tener más claro aquello que se deseaba con estos entes en el modelo de organización territorial, lo cierto es que esa certidumbre pronto se vería contaminada por la poderosa emergencia de unas Comunidades Autónomas que no se acababan de sentir cómodas con las correspondientes afirmaciones constitucionales. Así, no fue extraño que uno de los primeros conflictos significativos elevados ante el Tribunal Constitucional tuviese como protagonista la posición de la provincia en el mapa territorial que estaba emergiendo ${ }^{28}$. Hasta el día de hoy, se trata de preguntas sin respuesta. Hay que hacer notar que el protagonismo alcanzado por el debate autonómico ha llegado a postergar hasta extremos difícilmente aceptables la necesaria reflexión sobre la posición de los entes locales y, muy especialmente, de los municipios, no sólo en el nuevo reparto territorial sino también en el nuevo diseño del poder, con referencia incluida a las nuevas y precisas formas de gestión pública. No resulta exagerado decir que es esta una de las consecuencias más negativas del monopolio del debate autonomista.

Finalmente, resulta preciso referirse a un último protagonista. Último pero no el menos importante. Me refiero a las élites locales. Unas élites que habría que analizar desde una doble perspectiva, social y política. La importancia de las élites políticas en el desarrollo del nuevo modelo de Estado ha sido ya puesta de manifiesto, en particular con ocasión de la aprobación de los nuevos Estatutos de Autonomía ${ }^{29}$. Lo cierto es que desde poco después de los primeros procesos electorales autonómicos, esas élites han ocupado significativas posiciones de poder no sólo en relación con su espacio territorial natural sino también en el conjunto del Estado a través de su influencia en los correspondientes partidos políticos. Un fenómeno natural de autoalimentación ha propiciado que persiguiesen el incremento de las cuotas de autogobierno.

Pero sí notable ha sido y es el papel de las élites políticas, no menor importancia tiene el papel de las élites sociales. En paralelo al desarrollo y consolidación de la autonomía, se ha consolidado en la práctica totalidad de las Comunidades Autónomas una élite social que abarca los escenarios más significativos como empresa, sindicatos, universidad, entidades financieras, medios de comunicación o mundo de la cultura en general. Puede decirse que no se trata en puridad de un fenómeno novedoso, ya que las

28 Me refiero a la STC 32/1981 de 28 de julio que resuelve el recurso de inconstitucionalidad planteado por el Estado contra la Ley catalana 6/1980, de 17 de diciembre por la que se regula transferencia urgente y plena de las diputaciones catalanas a la Generalitat.

29 Al respecto, R. BLANCO VALDÉS, El largo viaje de España: de la invención del Estado autonómico al impulso hacia la confederación, ob. cit., pág. 4; F. SOSA WAGNER — I. SOSA MAYOR, El Estado fragmentado. Modelo austrobúngaro y brote de naciones en España, TrottaFundación Alonso Martín Escudero, 2006, pág. 197. 
élites regionales han existido siempre. Ello es así e, incluso, en muchos casos existirá una continuidad fácilmente detectable. Pero existen rasgos nuevos que no sólo modifican sus características como fenómeno sino que lo hacen de interés para un estudio del modelo autonómico. En general, esas élites se encuentran fuertemente ligadas al nuevo poder político, sea el que sea, y con él a la voluntad de disponer de determinadas cuotas de autogobierno. Con ello, también han sido sujetos activos de la mayor importancia en el fortalecimiento e incluso construcción de las denominadas señas de identidad. Desde una y otra posición, no sólo han alentado el crecimiento del autogobierno sino que han favorecido el desarrollo de un modelo político y social ajeno a la crítica y claramente proclive a visiones exclusivamente locales.

El papel de unos y otros ha sido determinante en la construcción y evolución del Estado constitucional español. Como casi siempre, los dioses enseñan las dos caras de la moneda. Si bien su papel ha sido esencial a la hora de construir la autonomía política y reforzar la identidad de las nuevas Comunidades Autónomas, especialmente de aquellas cuya autoafirmación política era menor, tampoco cabe desconocer los problemas inherentes a este modelo. Junto a la siempre criticable opacidad que en demasiadas ocasiones rodea la relación entre esos agentes sociales y el poder político, favoreciendo el desarrollo de relaciones demasiado cercanas, hay que llamar la atención sobre dos fenómenos significativos. Por una parte, el caldo de cultivo que este modelo ha significado para una visión particularista de España, e incluso del mundo. Abusando un poco de la exageración, resulta más fácil un traslado laboral fuera de nuestras fronteras que lograrlo a otra Comunidad Autónoma; se desconoce no sólo la geografía del vecino sino incluso una visión del Estado en su conjunto; un accidente es relevante si los muertos son murcianos, aragoneses o extremeños. Por otra, e íntimamente ligada a esa visión particularista cuando no excluyente que sustenta esa alianza de élites políticas y sociales, se pierde cualquier visión autocrítica. La reflexión crítica es expulsada y sólo cabe espacio para visiones idílicas que no sólo recrean el pasado, sino que lo mismo hacen con el presente relativizando sino eliminando los problemas, que en todo caso tienen una raíz ajena ${ }^{30}$.

Como es fácil entender, este modo de construir los espacios sociales autonómicos no sólo ha sido fundamental para facilitar el impulso autonómico y lograr un continuo incremento de los poderes autonómicos. Necesariamente, también ha tenido su incidencia en el modelo de Estado resultante fuera de cualquier visión territorial. Un Estado debilitado en algunos de sus aspectos naturales de cohesión, un Estado en el que un indeterminado poder central, normalmente aludido como Madrid, ha resultado imán de

30 Esta visión idílica y sin crítica del pasado colectivo se encuentra muy vinculada al reforzamiento de los símbolos identitarios en los nuevos Estatutos (J. TUDELA ARANDA, El camino perdido. La identidad en el proceso de reformas estatutarias, RarAP n. ${ }^{\circ} 33,2008$, págs. 107139). 
todas las maldades mientras que el ya muy notable poder descentralizado rehuía cualquier debate sobre posibles responsabilidades, incluso cuando el debate en cuestión tenía como objeto una materia descentralizada ${ }^{31}$. Un análisis más detenido de la erosión social que conlleva la idealización colectiva de los espacios autonómicos sería una parada necesaria en la reflexión no sobre el Estado autonómico sino sobre nuestra voluntad de ser como ciudadanos.

En todo caso, no puede dejar de soslayarse una de las características más significativas del proceso estudiado. En un espacio de tiempo muy breve, el Estado más centralizado de Europa desarrolló un modelo de descentralización comparable a muchos Estados de amplia tradición federal. La conversión de las históricas regiones en entes políticos dotados de una organización política y de muy amplias competencias legislativas y de gestión se hizo en un tiempo vertiginoso. Necesariamente, ello habría de conllevar que las carencias culturales propias de una tradición fuertemente centralista permaneciesen. Pero justo es decir que si se toma en consideración la intensidad y velocidad del proceso, las disfunciones fueron del todo menores.

\section{III.4. LA IRRUPCIÓN DE LA TERCERA ESPAÑA TERRITORIAL}

La tercera España territorial ya ha tenido ocasión de aparecer por estas páginas. Las líneas que siguen sólo quieren dar cuenta de algunos hitos que son esenciales no sólo para comprender su papel en el Estado autonómico sino también para extraer algunos datos que habrán de ser de interés para postreras reflexiones.

En 1992 los dos grandes partidos políticos de ámbito nacional acordaron resolver el problema planteado por las demandas de las denominadas Comunidades de vía lenta con la transferencia de la competencia de gestión de la educación y de otras materias menores. Con ello, se resolvería la incógnita abierta por el transcurso de los cinco años establecidos por el artículo 148 de la Constitución como límite para poder acceder al marco normativo previsto en el artículo 149. Hoy hace sonreír, pero es conveniente recordarlo, que los recelos de esos partidos ante esta operación eran tales que ni siquiera se planteó de primeras la reforma de los Estatutos como vía para esa transferencia sino que se operó mediante las correspondientes leyes orgánicas de transferencia. Sólo la presión de las Comunidades Autónomas acabó provocando que dos años más tarde se consumasen las correspondientes reformas estatutarias. Unas reformas que se limitaron estrictamente a la comentada transferencia competencial y que ni siquiera llegaron a abordar la eliminación de los muy importantes límites institucionales que estos Estatutos contenían. Límites que suponían una diferencia política más que notable entre estas Co-

31 Con claridad denuncia el profesor Contreras cuánto de rancio hay en esa alusión a Madrid (M. CONTRERAS CASADO, Las reformas de los Estatutos de Autonomía.., ob. cit., pág. 27). 
munidades Autónomas y aquellas que accedieron a la autonomía por el procedimiento del artículo 151 de la Constitución ${ }^{32}$.

De nuevo, la sonrisa emerge en el espectador curioso cuando recuerda que a la firma del pacto político que dio lugar a estas reformas, líderes de los dos grandes partidos políticos nacionales se apresuraron a decir que con ello se cerraba definitivamente el Estado autonómico. Sonrisa no ya por lo sucedido en los últimos años, sino porque tan sólo dos años después, en 1996, hay que realizar parada para referirse a un momento esencial de la evolución del Estado y que certificaba con elocuencia que nada se había llegado a cerrar.

La reforma de 1992-1994 fue una reforma protagonizada de forma exclusiva y excluyente por Partido Socialista y Partido Popular. En esa ocasión las Comunidades Autónomas fueron agentes casi meramente pasivos. Por ello, no podía extrañar que no en todas ellas fuese acogida con satisfacción una reforma que, al margen de la valoración que se hiciese sobre las transferencias realizadas o las que podían hacerse, lo cierto es que venía a certificar una diferenciación nítida entre unas Comunidades, aquellas que en los albores del proceso autonómico fueron calificadas en sus Estatutos como nacionalidades, y las restantes, calificadas como regiones. Como era lógico, el descontento fue especialmente intenso en las dos Comunidades, Aragón y Canarias, en las que la presencia de partidos nacionalistas-regionalistas era intensa y que, además, habían reiterado su voluntad de identificarse con las cuotas de autogobierno alcanzadas por aquellas nacionalidades. Las urnas vinieron a cerrar el puzle al resultar necesarios para el sustento parlamentario del nuevo gobierno del Partido Popular los votos de los representantes en las Cortes Generales del Partido Aragonés y de Coalición Canaria. La consecuencia fue inmediata. De nuevo, se procedía a la reforma de los Estatutos de estas dos Comunidades Autónomas.

Creo que en general se ha prestado escasa importancia a la significación que para el devenir global del Estado tuvo esa reforma. Bastaría recordar que con ella Canarias y Aragón tomaron la denominación de nacionalidad, eliminaron todas las limitaciones institucionales con la excepción de la posibilidad de celebrar elecciones en tiempo diferenciado y asumieron competencias tan notables como la gestión de la sanidad para entender su transcendencia. Pero su significación real deriva de que supuso el inicio de un proceso por el cual en los tres años posteriores el resto de Comunidades Autónomas seguirían sus pasos. La única salvedad fue la denominación de nacionalidad que se restringió a las dos Comunidades que habían iniciado el proceso. La consecuencia no pudo ser más significativa. El diseño del Estado autonómico, frente a lo que seguramente estaba en la mente de los constituyentes y desde luego de los dirigentes de Partido Popular y Partido Socialista en 1994 alcanzaba un nivel de homogeneidad muy notable. La diferencia verdaderamente sustancial se concentraba en la derivada del régimen de concierto para País

32 Sobre este proceso, E. AJA, El Estado autonómico. Federalismo y hechos diferenciales, ob. cit., págs. 81-94. 
Vasco y Navarra. Junto a ella, la singularidad de las Comunidades mal llamadas históricas quedaba reducida a la libertad para la decisión del tiempo de celebración de sus respectivos procesos electorales ${ }^{33}$.

Junto a este extremo, resulta conveniente llamar la atención sobre otras cuestiones anudadas a esta reforma. No es la de menor importancia resaltar que la misma supuso una quiebra en el modo de proceder habido hasta entonces en el desarrollo del Estado autonómico. Dos circunstancias la diferenciaron de los inicios y de la reforma de 1992-1994. En primer lugar, se acometió a impulso y por determinación de dos Comunidades Autónomas. El protagonismo de los partidos políticos de ámbito nacional fue menor. En segundo lugar, se inició sin consenso político. En esa ocasión, el impulso correspondía a un Partido Popular que requería de los votos de Coalición Canaria y Partido Aragonés y las reticencias, en ocasiones expresadas de forma rotunda y preocupada, al Partido Socialista que veía, de forma coherente con lo señalado en 1994, un exceso el impulso dado a la descentralización política. Como el lector habrá aventurado, no se trata sino de un perfecto precedente de lo sucedido, eso sí, con mayor radicalidad, diez años después.

Junto a ello, debe resaltarse el protagonismo de dos Comunidades Autónomas que desde el inicio del proceso autonómico se habían significado con fuerza bajo esa imagen de la tercera España territorial. Al respecto, hay que recordar que en Aragón el nuevo Estatuto, de forma difícilmente comprensible, lejos de satisfacer no hizo sino ahondar en una histórica sensación de agravio frente a las Comunidades vecinas de Cataluña y País Vasco. Tampoco puede omitirse que por primera vez la voz nacionalidad salía de lo que parecían sus fronteras naturales. La disponibilidad de este término y su asunción por Comunidades que en el imaginario político colectivo pertenecían al colectivo del común de las regiones habría de tener consecuencias notables, aunque nadie reparase en las mismas en aquellos días. Hoy, visto con la perspectiva otorgada por el debate provocado por los Estatutos de Autonomía de segunda generación, creo que se puede afirmar que en aquél momento se rompió el pretendido esquema constitucional de diferenciación entre nacionalidades y regiones con la consecuencia correspondiente de un mayor autogobierno para las primeras. Sin duda, la disponibilidad del término y, con él, de las mayores dosis de autogobierno era coherente con los mínimos exigidos por el principio democrático y por una visión no esencialista de la organización territorial. Pero quedaba por saber si ello sería aceptado por los partidos políticos nacionalistas que desde el inicio del proceso constitucional habían dejado clara su vocación de diferenciación. Los hechos han demostrado que no.

33 Siendo exactos, también seguía existiendo diferencias en relación con algunas competencias, pero en todo caso menores. Gestión de prisiones sólo la ostentaba Cataluña. También sólo esta Comunidad, además de País Vasco y Navarra, tenía la posibilidad de crear una policía autonómica. A Galicia y Andalucía se les había de transferir una compañía de la policía nacional. 
Porque si detrás de las reformas de 1996 y de las subsiguientes se encuentra con nitidez el debate de la simetría y la acumulación de todas las tensiones que acompañan al mismo, no es menos cierto que detrás del proceso de aprobación de los nuevos Estatutos se observa la misma dialéctica si bien en el sentido inverso de búsqueda de la diferenciación y de la singularización. Siendo una pregunta sin respuesta, no está de más plantearse si las exigencias de Cataluña hubiesen sido las mismas si los Estatutos de Autonomía de las Comunidades Autónomas de la denominada vía lenta hubiesen quedado en su redacción de 1994.

En todo caso, no debe pasarse por alto el respaldo que el proceso iniciado por Canarias y Aragón supuso para la consolidación de un modelo federal que la Constitución podía apuntar pero que no cerraba. No es sólo que de forma definitiva se generalizase una amplia y muy homogenea transferencia de poder a todos los territorios. Es también que con ese proceso crecía por una parte el quantum general de poder descentralizado y, sobre todo, se asentaba una cultura política descentralizada en la que inevitablemente crecía el juego de los actores políticos propios de un Estado federal. Existían, como habrá de verse, notables carencias para una definición ortodoxa del federalismo, sobre todo en el plno de la integración y relaciones intergubernamentales. Pero, esencialmente, resulta posible afirmar que el salto a la federalización se dió con el proceso comentado ${ }^{34}$.

\section{LA FRACTURA DE UN MODELO: LOS ESTATUTOS DE AUTONOMÍA DE SEGUNDA GENERACIÓN COMO REFLEJO Y EXPRESIÓN DE UNA MUTACIÓN CONSTITUCIONAL}

\section{IV.1. Las Raíces POLÍTICAS DEL PROCESO}

La disconformidad latente con la homogeneidad derivada del proceso de reformas estatutarias comenzado en 1996 acerca al necesario planteamiento de las raíces políticas que subyacen al proceso que finalizó con la aprobación de los hasta ahora seis textos de segunda generación. Son numerosas las raíces de ese árbol y algunas estarán directamente relacionadas con el debate territorial y otras habrá que buscarlas en territorios diferentes. Entre estas últimas creo que merece al menos reseñarse el clima que de relativización de la transición y sus éxitos se apoderó de una parte significativa del País coincidiendo con su 25 aniversario $^{35}$. El protagonismo de la escena política por

34 El profesor Carreras destaca como en el 2003 era muy poco lo que separaba a España de un Estado federal (F. DE CARRERAS, La reforma territorial: el cierre del modelo, ob. cit., pág. 1991).

35 Esta visión crítica de la transición ha sido reiteradamente transmitida en los últimos años tanto desde cierto discurso político como desde distintos sectores sociales. Su relación con la crítica al modelo autonómico es elocuente en el ya mencionado artículo de Ramoneda (J. RAMONEDA, La penúltima oportunidad, El País, 7 de septiembre). 
una generación diferente a aquella que la protagonizó fue un factor que coadyuvo notablemente a la misma. El estudio de esa relativización, de sus causas, de sus consecuencias, corresponde a otras páginas. En estas sólo corresponde constatar como ese clima favoreció a que muchos de los paradigmas del momento constituyente se debilitasen y se favoreciese su reforma.

En ese marco, o, si quiere, como presupuesto del mismo, se vivieron momentos políticos especialmente tensos durante la Segunda Legislatura del Presidente Aznar y, en particular, durante sus dos últimos años. Tensiones que afectaron muy directamente a las Comunidades Autónomas y en particular a las Comunidades de Cataluña y País Vasco. De manera inevitable, el rechazo a una forma concreta de actuar de un gobierno necesariamente coyuntural derivó en el descontento por la concepción global del Estado. Un descontento que tuvo un inmediato reflejo electoral con el auge de las formaciones nacionalistas más radicales.

En todo caso, y si bien es posible encontrar algunos paralelismos en las tensiones existentes en las dos Comunidades citadas, inmediatamente hay que advertir sobre la singularidad del descontento catalán. En efecto, durante años pudo pensarse que se había encontrado un acomodo a los deseos de autogobierno de Cataluña. Su posición en el conjunto del Estado era suficientemente diferenciada, su influencia por distintos canales formales e informales suficientemente notable y su capacidad de autogobierno suficiente y con margen de crecimiento ${ }^{36}$. El buen entendimiento de los líderes de CIU con Felipe González primero y con José María Aznar después, durante su primera Legislatura, favorecieron esta creencia. Sin embargo, aquél logro que sin temeridad podía enunciarse como uno de los grandes éxitos de la transición era más frágil de lo previsto y no soportó el embate de distintas circunstancias conjuntas de fuerza eso sí, no desdeñable. No fue la menor la pérdida por CIU del Gobierno de Cataluña. Junto a ella, no pueden obviarse los evidentes errores que en materia autonómica fueron cometidos por el segundo gobierno de Aznar. Errores que, además, más allá del terreno de lo sustantivo alcanzaron el terreno siempre inflamable de lo simbólico. Junto a ello, una paulatina percepción de un trato injusto en el terreno de las cargas financieras, algo por lo demás obvio si se comparaba con el País Vasco. Si a ello se añade un clima general favorable a percepciones identitarias tanto por las políticas educativas realizadas durante más de veinte años como por movimientos ideológicos más globales, resultará fácilmente comprensible que se agudizase una sensación de descontento general con la fórmula vigente de Estado autonómico que habría de materializarse en el éxito electoral de Esquerra Republicana.

36 Entre esos factores, entre lo formal y lo informal, merecería por su importancia un análisis detallado el derivado de la influencia añadida sobre el conjunto del Estado de aquellas Comunidades que, como la catalana y la vasca, disponían de partidos políticos nacionalistas que con sus votos llegaban incluso a condicionar el signo del gobierno del estado (sobre este extremo, R. BLANCO VALDÉS, Nacionalidades históricas y regiones sin historia, ob. cit., págs. 163-167). 
De esta forma, la necesidad no de una reforma del Estatuto de Autonomía sino la aprobación de uno nuevo que modificase incluso con radicalidad los términos de la presencia de Cataluña en el Estado autonómico se adueñó de la agenda política catalana. Además, en esta ocasión el mayor impulso correspondía a un Presidente socialista de la Generalitat. Como es de todos sabidos, el debate adquirió un matiz singular como consecuencia de la victoria electoral del líder socialista José Luis Rodríguez Zapatero en los comicios generales de 2004 y de su previo pronunciamiento electoral sobre el respeto absoluto a cualquier propuesta que surgiese del Parlamento de Cataluña. De forma un tanto repentina, sin que existiese conciencia exacta por parte de los principales agentes implicados, desde Cataluña se proponía un salto que suponía mucho más que una reforma del Estatuto. Se planteaba, ninguno de los proponentes lo negaba, un nuevo modelo de relaciones con el Estado, desde la refundación del mismo.

En este marco, cabe adelantar una nota del proceso estudiado que se antoja importante. Si bien en principio podría afirmarse que esta etapa de la descentralización territorial en España ha sido impulsada exclusivamente desde las Comunidades Autónomas y que la reforma de sus Estatutos respondió a deseos exclusivamente de esos territorios, lo cierto es que fue un proceso con protagonismo compartido con el propio Estado central, al menos en su momento clave, la tramitación y posterior aprobación de un nuevo Estatuto para Cataluña. En efecto, una de las banderas ideológicas del paradigma político resultante de las elecciones generales de 2004 era el de la denominada España plural. Una denominación vaga e inconcreta pero que encubría un aval general a apuestas de profunda ampliación del contenido político y jurídico de las Comunidades Autónomas. Incluso podía observarse la reiteración de una premisa difícilmente compartible. En efecto, se decía y reiteraba que habían pasado muchos años desde la aprobación de los Estatutos y que la calidad de la autonomía lejos de mejorar, se había degradado. Sin obviar imprescindibles matices, lo cierto es que cualquier observador podía observar que la letra de esos Estatutos, muchos de los cuales habían tenido significativas e incluso recientes reformas, había dado mucho de sí. Las Comunidades Autónomas eran una realidad política y administrativa que poco tenía que ver con una lectura literal de esos textos ${ }^{37}$. Pero, de forma coherente con la anticipada relativización de la transición y sus éxitos, de pronto parecía necesario reinventar el Estado, adaptándolo a una ideología más moderna y libre. Porque, es preciso reiterarlo, el modelo de reforma planteado desde la propuesta de Estatuto de Autonomía de Cataluña distaba mucho de ser una mera revisión de la norma estatutaria a objetos de actualización ${ }^{38}$.

37 Como indica el profesor Blanco Valdés, los Estatutos de Autonomía se habían aggiornado por encima de las propias reformas que llegaron a tener, R. BLANCO VALDÉS, El largo viaje de España: de la invención del Estado autonómico al impulso hacia la confederación, ob. cit., pág. 17.

38 Desde esa perspectiva, necesariamente, el debate sobre la oportunidad de las reformas habría de plantearse en términos bien diferentes (J. CANO BUESO, Una reflexión sobre el Estado autonómico, ob. cit., págs. 4-11; F. CAAMAÑO DOMÍNGUEZ, Las necesidades de reforma cons- 
Pero no fue Cataluña la única Comunidad que buscó la reforma de su Estatuto. Con formas y contenidos diferentes, desde el País Vasco se presentó a debate una propuesta estatutaria comúnmente denominada Plan Ibarretxe que abiertamente cuestionaba no ya los principios del Estado autonómico sino al propio Estado ${ }^{39}$. Detrás de la misma latía por parte de los proponentes su voluntad de buscar una solución a lo que denominaban conflicto vasco. En estas páginas sólo interesa destacar que si bien con unas características singulares que forzosamente la separan del debate autonómico general, no puede dejar de obviarse el significado de ese documento en el momento de analizar la realidad territorial de España. También es importante constatar que el mismo, debido a su manifiesta inconstitucionalidad en cuestiones esenciales, no llegó a ser tomado en consideración por las Cortes Generales. En todo caso, el debate que precedió a esa votación fue sumamente ilustrativo y ejemplo del mejor Parlamento.

Ese rechazo abre necesariamente el interrogante del por qué en cambio se votó afirmativamente la toma en consideración y posterior tramitación de la propuesta de Estatuto de Autonomía remitida por el Parlamento de Cataluña. La pregunta cobra todo su sentido si se recuerda que, como hoy es común acuerdo, dicho texto era manifiestamente inconstitucional en cuestiones también esenciales ${ }^{40}$. De hecho, uno de los objetivos de la tramitación no fue otro que el de eliminar esas posibles contradicciones con el texto constitucional. Pero si esa operación se consideraba posible con el texto catalán, realmente podía pensarse en algo semejante con el Plan Ibarretxe. Si en este caso no se hubiese llegado a acuerdo, la responsabilidad de la retirada hubiese correspondido a los proponentes.

Seguramente, la opción más racional jurídicamente, dada no sólo la redacción sino el espíritu y objetivo de los dos textos hubiese sido el de no tomar en consideración ninguno de los dos, abriendo una nueva oportunidad de diálogo en las respectivas Cámaras autonómicas, lejos de cualquier dogmatismo. Pero, al igual que sucedió en 1996, prevalecieron intereses de partido. En este caso, era el Partido Socialista el que necesitaba de los votos de

titucional y estatutaria del Estado autonómico en el vol. col. Reformas territoriales. Jornadas de sigüenza, ob. cit., págs. 128-138; J.J. SOLOZABAL ECHAVARRÍA, La reforma constitucional en clave federal en su volumen Tiempo de reformas..., ob. cit., págs. 371-382).

39 Sobre el denominado Plan Ibarretxe. J.J. SOLOZÁBAL ECHAVARRÍA, Reflexiones constitucionales sobre la propuesta de modificación estatutaria de Ibarretxe en Tiempo de reformas..., ob. cit., págs. 107-139; E. GUEVARA SALETA, La reforma del Estatuto de Autonomía vasco en Jornadas de Sigúenza. Reformas territoriales, Editorial Pablo Iglesias, págs. 241-248; J. M. CASTELLS ARTECHE, La reforma estatutaria vasca en La reforma del Estado autonómico, ob. cit., págs. 129-148.

40 Sobre el proyecto de reforma del Estatuto de Autonomía de Cataluña, J.J. SOLOZÁBAL ECHAVARRÍA, Sobre las reformas estatutarias y la propuesta del Parlamento Catalán en Tiempo de reformas.., ob. cit., págs. 141-174; M. CORRETJA TORRENS, La reforma del Estatuto de Autonomía de Cataluña en La reforma del Estado autonómico, ob. cit., págs. 111-128; C. VIVER I PI-SUNYER, La reforma del Estatuto de Autonomía de Catluña en Jornadas de Sigüenza..., ob. cit., págs. 149-160. 
un Partido Nacionalista, Esquerrra Republicana, para conformar su mayoría en las Cortes Generales.

Aunque ya ha habido ocasión de hacer una mínima referencia a ello, no deben perderse de vista los cambios ideológicos acaecidos en la sociedad contemporánea desde la aprobación de la Constitución y los primeros Estatutos de Autonomía. No es el menor el resurgir de la identidad como elemento central del debate ideológico. Desde el mismo, la identidad ha transcendido como era inevitable a la esfera de la política. La identidad colectiva de pueblos y naciones se convierte en bandera política y con ella el nacionalismo ha adquirido un notable impulso. Los textos de los nuevos Estatutos son fiel reflejo de la sensibilidad de sus redactores a las ideas identitarias ${ }^{41}$.

La idea de la fuerza de la identidad acerca a una última reflexión sobre las raíces políticas del proceso de aprobación de los nuevos Estatutos. La idea política de la España plural se traducía en el objetivo tangible de que "que los nacionalistas, incluso los independentistas, se sientan a gusto en el Estado". La contradicción es evidente. Se trata de un objetivo imposible. Un nacionalista moderado lo más que puede aspirar es a conllevar su estar en el Estado. Un nacionalista radical nunca podrá siquiera conllevar. Su objetivo, plenamente legítimo, es incompatible con el Estado. Por ello, una vez más en la historia, los buenos deseos cubren un grave error político. Perseguir esa comodidad nacionalista sólo puede hacerse desde un debilitamiento excesivo del Estado. Y si es legítimo que un nacionalista persiga la independencia incluso desde la erosión del Estado al que pertenece, siempre, claro está, que se limite al ejercicio de la política y se excluya el uso de cualquier violencia, no sólo será legitimo sino que será obligación para el gobernante del Estado reforzar el mismo y evitar en la medida de lo posible cualquier política de erosión por parte de aquellos que no desean la pervivencia del Estado en sus términos actuales.

IV.2. LOS TÉRMINOS JURÍDICOS. LA MUTACIÓN DEL ORDENAMIENTO CONSTITUCIONAL DE LA ORGANIZACIÓN TERRITORIAL

El título del epígrafe bajo el que se escribe estas líneas puede resultar engañoso. Como es obvio, resulta imposible examinar como es debido los complejos presupuestos jurídicos en los que se ha movido la aprobación de los Estatutos de segunda generación y, muy particularmente, el de Cataluña.

41 La fuerte presencia de la reivindicación identitaria en los nuevos Estatutos es una de sus notas más destacadas (M. CONTRERAS CASADO, Las reformas de los Estatutos de Autonomía. Viejos y nuevos tiempos en la construcción del Estado autonómico, Anuario Jurídico de La Rioja n. ${ }^{\circ} 11$, 2006, págs. 18-19; J. TUDELA ARANDA, El camino perdido. La identidad en el proceso de reformas estatutarias, ob. cit., págs. 107-139; J. PEMÁN GAVÍN, El sistema español de autonomías territoriales..., ob. cit., págs. 28-29; C. VIVER I PI-SUNYER, ¿Grandes reformas o pequeños pasos?.., ob. cit., pág. 33). 
Con riqueza cuantitativa y cualitativa, la doctrina ha debatido acerca de la casi totalidad de cuestiones que una reforma tan significativa ponía encima de la mesa ${ }^{42}$. Por ello, para un examen detenido de los términos de ese debate resulta imprescindible acudir a esa rica doctrina ${ }^{43}$. En estas líneas sólo cabrá llamar la atención sobre algunos de los extremos más notables del mismo, cuestiones no tanto de detalle, por más importancia que puedan tener sino estructurales para el objetivo final. Y no tanto para sumar una voz a esos diálogos doctrinales como para servirse de los mismos al objeto de iluminar la globalidad del proceso autonómico. Como se indicó, la intención de estas páginas más que realizar un riguroso excursus jurídico es reflexionar desde el ensayo sobre lo que ha sido la evolución del principio constitucional de autonomía y lo que esa evolución significa en el presente para el Estado.

Si se alude a presupuestos jurídicos, es inevitable recordar en primer lugar como la discusión sobre el Estatuto de Autonomía de Cataluña ha llegado a afectar a los presupuestos teóricos que parecían unánimemente aceptados en torno a la Constitución. Desde luego, puede considerarse esta afirmación como excesiva. Pero lo cierto es que el impulso que se deseaba dar a las normas estatutarias, así como la posibilidad de incluir en ellas determinados contenidos, llego a generar una cultura de cierta relativización de la jerarquía de la Constitución en relación con los Estatutos. De alguna manera, el denominado mito del Estatuto-Constitución, descansaba en una visión de la relación Constitución-Estatuto de Autonomía más horizontal que vertical ${ }^{44}$. Como es lógico, desde la otra cara de la moneda, este debate supuso también una revisión de las visiones más clásicas sobre la naturaleza jurídica de los Estatutos de Autonomía. Y al respecto resulta conveniente señalar que frente a posiciones que pudieron tener su razón de ser en los albores del desarrollo constitucional y que prácticamente identificaban los Estatutos con las leyes orgánicas, el debate al que se alude sirvió para, definitivamente, posicionar a la norma estatutaria como una norma singular, complemento imprescindible de la Constitución ${ }^{45}$. Así, conviene tener presente que el debate, incluso agrio

42 Para una visión general, F. LÓPEZ RAMÓN (Ed.), De la reforma estatutaria, Monografías de la Revista Aragonesa de Administración Pública VIII, 2005; VV.AA., Las reformas estatutarias y la articulación territorial del Estado, AELPA-Tecnos, 2008.

43 Una bibliografía general cuando sólo restaba por aprobar el Estatuto de Autonomía de Castilla y León: A. GARCÍA de la OLIVA; M. JULIANI AGUADO, Bibliografía sobre la reforma de los Estatutos de Autonomía, RCG n. ${ }^{\circ}$ 66, 2005, págs. 360-402.

44 Esta denominación surge de la obra del profesor Muñoz Machado (S. MUÑOZ MACHADO, El mito del Estatuto Constitución en La reforma del Estado autonómico, ob. cit., págs. 65-84).

45 Desde luego, los matices, incluso las diferencias, sobre la posición que al Estatuto le corresponde en relación con la Constitución, son importantes. Pero, en todo caso, se observa una revalorización de la norma estatutaria más conforme con su posición en el sistema de fuentes y con la estructura general del Estado autonómico. Al respecto, J. M. CASTELLÀ ANDREU, La función constitucional del Estatuto de Autonomía de Cataluña, Instituto de Estudios Autonómicos, 2004, 239 págs. Por su parte, García Roca señala como esa visión cuasi constitucional de los Estatutos, no puede ocultar que no son Constitución y que se encuentran subordinados a ésta (J. GARCÍA ROCA, El riesgo de generalización de las aimetrías en las reformas estatutarias en La 
en ocasiones, sobre la posición de los Estatutos de Autonomía en nuestro ordenamiento jurídico, ha servido, como siempre sucede cuando se discute desde el rigor, a una visión más rica y compleja de la ordenación jurídica del Estado autonómico en sus principales fuentes.

Entre los recordatorios necesarios al examinar los presupuestos jurídicos, se encuentra también el de las omisiones. Entre ellas, ninguna de tanta importancia como el olvido de una anunciada reforma constitucional que habría de ser presupuesto de una federalización del Estado, entendiendo por la misma la reforma del Senado y la profundización en los principios e instrumentos de colaboración propios de todo Estado descentralizado. Si se hace memoria, puede recordarse que lograr este objetivo fue el motivo de la irrupción en la agenda política de la reforma del modelo territorial con la conferencia celebrada en Santillana del Mar por el Partido Socialista en septiembre de 2003. Como es sabido, si bien la citada reforma fue incluida por el candidato Rodríguez Zapatero en su primer discurso de investidura apenas seis meses después de esa conferencia, la misma fue orillada y hoy ha sido expresamente postergada a un futuro indeterminado. Si en cualquier momento una reforma constitucional resulta compleja y necesita de urdir significativas complicidades políticas, en tiempos de enfrentamientos que acaban con casi todos los puentes, resultan imposibles. Y así fueron esos años ${ }^{46}$.

Cerrada la vía de la reforma constitucional, sólo permanecía abierta la de unos Estatutos de Autonomía que, aparentemente, se encontraban muy cerca de haber agotado sus posibilidades dentro del marco dibujado por la Constitución. Como suele suceder, ya se dijo, pudo la razón política a la razón jurídica y se inició la reforma del modelo territorial desde los Estatutos de Autonomía sin haber sentado los presupuestos de la misma en su sede natural, la Constitución. Más allá, se inició esa reforma sin que existiese en perspectiva una visión clara del modelo de Estado al que se quería llegar ${ }^{47}$. Las consecuencias, habrán de verse, son numerosas. Pero, aun a la espera del pronunciamiento del Tribunal Constitucional sobre el Estatuto de Autonomía de Cataluña, y sea cual sea el mismo, cabe señalar que los nuevos textos inevitablemente llaman a una comprensión diferente de la relación entre la Constitución y los Estatutos de Autonomía.

No puede omitirse otro presupuesto directamente anudado al anterior. La reforma del modelo territorial desde los Estatutos inevitablemente habría de favorecer una visión centrípeta del Estado. Además, al realizarse no desde un acuerdo político previo sino al impulso de los acuerdos logrados en cada

reforma del Estado autonómico, ob. cit., pág. 107). En sentido similar, F. De CARRERAS, La reforma territorial: el cierre del modelo, ob. cit págs. 121.

46 Una temprana advertencia sobre los riesgos de separar los procesos de reforma estatutaria de la reforma constitucional la realizó el profesor Ortega (L. ORTEGA ÁLVAREZ, Reforma Constitucional y Reforma Estatutaria, Thomson-Cívitas, 2005, págs. 13-52).

$47 \mathrm{La}$ inexistencia de un plan que guiase todo el proceso ha sido una de las críticas más generalizadas al mismo (por todos, J. PEMÁN GAVÍN, El sistema español de autonomías territoriales, ob. cit., pág. 5). 
Comunidad Autónoma, abría paso a una visión necesariamente fragmentaria del Estado ${ }^{48}$. Presión centrífuga y fragmentarismo no pueden considerarse sólo como consecuencias del proceso. Lo son. Pero se encontraban claramente predeterminadas en las decisiones desde las que se inició el mismo. Es decir, difícilmente podrá señalarse que no fueron queridas. Responden a una determinada visión del Estado. A una determinada visión jurídico-política del mismo en lo territorial.

Ello se reafirma si se recuerdan algunos términos del debate académico que ha acompañado este proceso. En numerosas ocasiones se llamó la atención sobre los riesgos no ya políticos sino relativos a la erosión del necesario rigor en la ordenación jurídica del Estado. Junto a ello, hay que recordar que a instancias del propio Gobierno, el Consejo de Estado tuvo ocasión de emitir un Dictamen sobre los términos de una eventual reforma constitucional que contenía un parecer extenso y pormenorizado de los términos en los que podría afrontarse una reforma del Título VIII de la Constitución y desde la misma, en su caso, de los Estatutos de Autonomía. No suficientemente se ha llamado la atención sobre el valor y riqueza de este pronunciamiento que en medio de las fuertes tormentas que rodearon el debate acabó en el olvido como el propio objetivo de reforma del texto constitucional ${ }^{49}$.

Desde ese olvido, como se indicó, se buscó en los Estatutos sustanciar las carencias denunciadas en torno al autogobierno de las Comunidades Autónomas. Se perseguía no sólo incrementar cuotas de autogobierno sino también la calidad del mismo ${ }^{50}$. Así, no es de extrañar que no se buscase reformar los Estatutos existentes. La voluntad de las Comunidades que iniciaron el proceso, la Comunidad Valenciana con una confusa técnica sería la excepción, fue la de proceder a la aprobación de nuevos Estatutos. No es un dato menor. Hasta esa fecha había habido, como se ha examinado, muchas e importantes reformas, si bien todas de Estatutos de Comunidades de la denominada vía lenta. Ahora se quería dejar claro que se trataba de un proceso nuevo, que se abría una nueva etapa, en definitiva, que se quería superar un tiempo que se consideraba periclitado.

En este punto resulta forzoso realizar una matización. Si sólo desde una visión de conjunto de los seis Estatutos aprobados es posible conocer el alcance y consecuencias que para el conjunto del Estado tiene el proceso examinado, lo cierto es que no son iguales entre sí ni someten al Estado a las

48 Sobre los riesgos del fragmentarismo inherente al procedimiento seguido han advertido, entre otros y en momentos bien diferentes: J. GARCÍA ROCA. El riesgo de generalización de asimetrias en las reformas estatutarias, ob. cit, págs. 92-97; J.PEMÁN GAVÍN, El sistema español de autonomias territoriales..., ob. cit., págs. 8-12.

49 Vid, F. RUBIO LLORENTE y J. ÁLVAREZ JUNCO (Coords.), El informe del Consejo de Estado sobre la reforma constitucional. Texto del informe y debates académicos, CEPC, Madrid, 2006.

$50 \mathrm{Al}$ respecto, C. VIVER i PI-SUNYER, F. BALAGUER CALLEJÓN y J. TAJADURA TEJADA, $L a$ reforma de los Estatutos de Autonomía. Con especial referencia al caso de Cataluña, CEPC, 2005. 
mismas tensiones ${ }^{51}$. Así, resulta difícil negar que es el Estatuto de Autonomía de Cataluña el que plantea mayores problemas de encaje en los parámetros del Estado autonómico, incluso en su versión más descentralizadora. Se ha señalado, no sin razón que numerosos preceptos de otros Estatutos, y particularmente del de Andalucía, son idénticos a otros contenidos en el de Cataluña y que si bien estos han sido recurridos ante el Tribunal Constitucional, no lo han sido los de los otros textos. Ello es cierto y sin duda llama la atención sobre algunas de las sinrazones del proceso. Lo que se rechaza en una Comunidad Autónoma se vota a favor en otras. Pero, aceptando lo anterior, lo cierto es que ninguno de los cinco Estatutos restantes pueden identificarse con el de Cataluña, ni siquiera al de Andalucía. La diferencia, esencial para entender lo que de mutación constitucional encierra el proceso de reformas, a salvo de la Sentencia del Tribunal Constitucional, se encuentra en los fundamentos ideológicos del Estatuto de Autonomía de Cataluña. Si nadie puede deducir de la lectura del Estatuto andaluz una voluntad confederal o de ser algo diferente al Estado, no sucede lo mismo con el texto catalán. Desde su preámbulo, los guiños a la afirmación de una entidad política y culturalmente diferenciada que se relaciona con el Estado en términos igualdad son evidentes. Letra y música suenan a canción confederal, deseo, por otra parte, largamente reiterado por muchos de sus impulsores ${ }^{52}$.

El Estatuto de Autonomía de Cataluña y, en menor medida e intensidad diversa, los restantes Estatutos, descansan sobre unos presupuestos ideológicos que poco parecen tener que ver con aquellos que se venía creyendo habían fundamentado la afirmación constitucional de la autonomía y el posterior desarrollo de este principio. No se trata de una ideología de integración. Desde sus preámbulos, incorporados en esta segunda generación, los textos manifiestan una permanente tensión desde la autoafirmación y diferenciación, sin que sea posible vislumbrar en los mismos otras referencias al conjunto del Estado y de la Nación que no sean estrictamente reivindicativas $^{53}$. Así, son textos que han hecho de la identidad, una de sus banderas. Afirmación identitaria que necesariamente tenía que tener como corolario forzado el reforzamiento de la afirmación de la bilateralidad como forma principal de relación entre el Estado y las Comunidades Autónomas ${ }^{54}$. Por otra parte, su vocación de reinterpretar algunos preceptos constitucionales ha sido manifiesta, singularmente en relación con el orden competencial me-

$51 \mathrm{Al}$ respecto, J. CANO BUESO, Una reflexión sobre el Estado autonómico, ob. cit., pág. 3.

52 En este sentido, R. BLANCO VALDÉS, El largo viaje de España: de la invención del Estado autonómico al impulso hacia la confederación, ob. cit., pág. 13. Al respecto, conviene aclarar que para negar los vientos confederalistas no es suficiente una lectura fragmentaria del Estatuto. Las normas poseen su propia patina y ésta sugiere y advierte del futuro muchas veces más que ninguna declaración expresa.

53 Sobre el valor y significado de los preámbulos en los nuevos Estatutos, M. CONTRERAS CASADO, Las reformas de los Estatutos de Autonomí..., ob. cit., pág. 22.

54 Entre otros, R. BLANCO VALDÉS, El largo viaje de España: de la invención del Estado autonómico al impulso hacia la confederación, ob. cit., pág. 6; J. PEMÁN GAVÍN, El sistema español de autonomias territoriales, ob. cit., pág. 23. 
diante la denominada técnica del "Blindaje competencial". Si a ello se suma el alcance de la incorporación a los mismos de materias tan simbólicas como los derechos y libertades, el Poder Judicial o las relaciones exteriores, pocas dudas podrán quedar sobre la voluntad de sus autores de refundar el modelo de organización territorial vigente ${ }^{55}$.

\section{IV.3. La heterogeneidad COMO RESUltado DEL PROCESO}

Ha habido ocasión suficiente de denunciar la heterogeneidad del mapa autonómico como una de las consecuencias más evidentes del proceso de reformas estatutarias. Como se indicó, tras las reformas iniciadas en el año 1996, se alcanzó entre las diecisiete Comunidades Autónomas una práctica uniformidad con la singularidad, no menor, derivada de la interpretación hecha del reconocimiento de los derechos históricos para País Vasco y Navarra. Hoy, por el contrario, cuatro años después de la aprobación del Estatuto de Cataluña y dos después del último reformado, la heterogeneidad es absoluta. No es sólo que exista diferencia entra las seis Comunidades que han reformado sus Estatutos y las once restantes. Es que entre los seis textos aprobados hay diferencias sustanciales. Así, esquemáticamente puede decirse que los de Cataluña y Andalucía se mueven en un plano de vanguardia tanto en forma como en fondo, si bien con unas diferencias ideológicas tan sustanciales que obliga a diferenciarlos. De los restantes, los textos de Aragón y Castilla-León se moverían en un plano intermedio, representando no sólo la España de la comodidad territorial, la España de las identidades realmente plurales y no conflictivas, sino también una voluntad de apurar al máximo la Constitución en el deseo de actualizar el Estatuto pero sin llegar a someterla a tensiones radicales. Finalmente, tanto por consideraciones formales como de fondo, los textos de Comunidad Valenciana e Islas Baleares representarían las reformas de menor calado, si bien también con diferencias, ya que el texto balear se encuentra con claridad un peldaño por encima del valenciano.

La fragmentación del modelo plantea por sí mismo notables interrogantes. No es la menor si se trata de una situación transitoria, una vez más, o si, por el contrario, se trata de la consagración de una estática de la organización territorial. Lo más probable es que no se trate ni de una cosa ni de otra. No parece posible hablar de estática, de estación término. Los años transcurridos han demostrado sobradamente que decir que el modelo de organización territorial se ha cerrado es más que aventurado. Además, hay elementos objetivos que no invitan a ello. Así, el hecho de que existan Comunidades Autónomas que han intentado la reforma de sus Estatutos de Autonomía sin éxito en su paso por las Cortes Generales u otras que, como es el Galicia, lo han intentado con firme voluntad política pero no han llegado a alcanzar el

$55 \mathrm{Al}$ respecto, M. CONTRERAS CASADO, Las reformas de los Estatutos de Autonomia..., ob. cit., pág. 21. 
consenso necesario en la Cámara autonómica, sería suficiente para pensar que no se ha cerrado el mapa. A ello pueden sumarse otras circunstancias como deseos reformistas nacidos al amparo de posibles beneficios obtenidos por algunas Comunidades Autónomas por mor de los nuevos textos o, incluso, el disgusto expresado por numerosas fuerzas políticas y personalidades catalanas por un texto que consideran se aleja demasiado de las aspiraciones de esa Comunidad.

En todo caso, aún abierto, lo que parece claro es que en ningún caso la homogeneidad será el resultado del proceso. Son muchas las razones que me llevan a esta afirmación. No es la menos relevante percibir que la tensión social de demanda de mayores cuotas de autogobierno plasmadas en las correspondientes reformas estatutarias, ha llegado a su límite en muchas Comunidades Autónomas. Así parecen haberlo entendido los propios partidos políticos cuando transcurridos ya unos años desde el inicio de la Legislatura en curso no han planteado entre sus prioridades la correspondiente reforma estatutaria en aquellas Comunidades Autónomas que no la han llevado a cabo hasta la fecha ${ }^{56}$. Por otra parte, aun en el caso de que esos procesos de reforma se iniciasen, es impensable que el texto resultante poseyese una letra y contenido similar al aprobado en Cataluña.

Esta característica hace más difícil definir nuestro modelo de Estado. Es cierto que la asimetría existe en Estados descentralizados. Pero, puede decirse, responde a una pauta más ordenada, cuando no a una singularidad muy específica como puede ser el caso de Escocia en Gran Bretaña o Quebec en Canadá. Una lectura fría del mapa autonómico resultante tras este proceso de reformas no puede evitar una cierta sensación de confusión. Confusión que, querellas nominalistas al margen, difícilmente no repercutirá en el funcionamiento del Estado considerado en su conjunto

\section{EL ESTADO RESULTANTE. ORGANIZACIÓN TERRITORIAL Y CAPACIDAD DEL ESTADO}

\section{V.1. El Estado DEsconcertado}

Necesariamente, la constatación de la heterogeneidad del modelo de Estado derivado de los nuevos Estatutos de Autonomía, me ha acercado a una valoración del Estado que deriva del proceso. Examinar y enjuiciar ese resultado no es, no es sólo, enjuiciar el modelo de organización territorial. Es, y es ante todo, describir el Estado. Sin adjetivos. Es intentar acercarse al Estado en el que hoy viven cerca de 45 millones de personas, al Estado que afronta el reto de mantener la calidad de vida y conquistas sociales adquiri-

56 En este sentido, también es significativo que el Partido Popular que rechazó la reforma del Estatuto de Autonomía promovida por Partido Socialista y Bloque Nacionalista Galego, recuperase el poder en Galicia. 
das en el contexto de una histórica crisis económica. Precisamente, éste es un dato que no puede obviarse. La crisis no es un mero apunte coyuntural. Desde luego, ésta pasará y vendrán tiempos mejores. Pero vendrán otras. Y es en estas circunstancias en las que especialmente habrá que comprobar la eficacia del modelo de Estado del que nos hemos dotado. En cualquier caso, paradoja no querida, hoy, aun balbuceante en sus nuevas estructuras, el Estado ha de saber responder a una situación especialmente compleja. Por ello, el proceso de reformas también debe enjuiciarse desde su repercusión en el conjunto de la eficacia y eficiencia de la gestión pública en España ${ }^{57}$.

He tenido ya ocasión de describir el Estado resultante como desconcertado $^{58}$. Consideré, y sigo estimando, que es una adjetivización expresiva de aquello que se ofrece no sólo a los ojos del estudioso sino ante los de cualquier ciudadano que repare reflexivamente en estos temas o, simplemente llegue a verse afectado por alguna de sus contradicciones. El desconcierto, cabe advertirlo inmediatamente, tiene raíces más allá del proceso de reformas que ha transformado la organización territorial. Se trata de una paradoja ideológica que si bien comprensible no sólo en los primeros años del Estado autonómico sino incluso bien avanzado éste, se hace más difícil de entender no ya pasados treinta años sino cuando, además, desde el propio edificio central del Estado se ha impulsado un proceso semejante de descentralización. La paradoja no es otra que la que deriva de impulsar procesos descentralizadores cuando, simultáneamente, se desea retener el poder de decisión incluso en ocasiones en temas menores o se rechaza, en todo caso se acepta de mala gana, que en determinados asuntos las Comunidades Autónomas opten por decisiones diferentes de las adoptadas por el Gobierno del Estado. De alguna manera, puede decirse, reconduciéndolo a términos ideológicos, por un lado se alienta la autonomía y su inevitable diversidad y, por otro, se llama al escándalo ante esa diversidad y se reclama un poder superior de decisión

Ante muchas decisiones, los ejemplos serían recurrentes y cotidianos, uno tiene la sensación de que se ha llevado al Estado a un punto al que no se quería llegar. O, quizá, que no se era plenamente consciente de a dónde se iba cuando se respaldaron con entusiasmo las reformas que hoy conllevan opciones autonómicas que se rechazan o impiden tomar decisiones que se consideran pertinentes. Hay que advertir que no se trata de un desconcierto que afecte sólo al gobierno y al partido que impulsó este proceso de reformas. Si uno mueve la cabeza advierte que todos los partidos nacionales están sumidos en una situación semejante. Así, es normal oír en líderes nacionales del principal partido de la oposición mensajes contradictorios con aquello que postulan sus líderes autonómicos e, incluso, con lo que se dice cuando el discurso se pronuncia en sede autonómica.

57 . Sobre este punto, J. PEMÁN GAVÍN, El sistema español de autonomías territoriales, ob. cit., pág. 22.

58 Vid, J. TUDELA ARANDA, El Estado desconcertado y la necesidad federal, Cívitas-Fundación Alonso Martín Escudero, 2009, 266 págs. 
Junto a ello, el Estado apenas disimula su incapacidad de reacción ante los desafíos soberanistas más rotundos. De manera perceptible, una marea de desafíos ha ido creciendo sin que se advierta reacción alguna por parte del Estado. No se trata, debe quedar claro, de reacción jurídica, que, por supuesto, también puede ser necesaria. Se trata del rearme ideológico del Estado. Negar la existencia de un proceso de debilitamiento de la consideración unitaria del Estado, de debilitamiento de los factores de cohesión nacional, resulta peligroso. No se trata de una materia sencilla. Los sentimientos se alteran con facilidad. En unos y otros pueden crecer y crecen posiciones radicales de incomprensión frente al otro ${ }^{59}$.

Más allá de las razones que explican este acontecer, varias pero esencialmente reducidas a un olvido de visiones de Estado para predominio de las exigencias electorales más inmediatas, este fenómeno se relaciona con otro de gran importancia no sólo para el desarrollo de la organización territorial sino para el propio devenir político de nuestro Estado. Me refiero a la incidencia que la construcción autonómica y su devenir ha tenido sobre la estructura de partidos. Puede decirse que es difícil saber que es antes si el huevo o la gallina. Si han sido las élites políticas locales las que han provocado el fortalecimiento del poder autonómico y con ello, inevitablemente, un debilitamiento de las estructuras nacionales de los partidos o si, por el contrario, ha sido esa evolución de las Comunidades las que ha otorgado a las élites un poder del que carecían en los partidos nacionales. Lo cierto es que la posición de los partidos como sujetos de integración nacional se ha debilitado considerablemente y en ocasiones fundamentales, como ha demostrado la aprobación de los nuevos Estatutos de Autonomía, ha hecho imposible la adopción de criterios homogéneos, imponiéndose los criterios territoriales. También los partidos tienen el síndrome del desconcierto y desde el mismo poco ayudan al concierto del Estado ${ }^{60}$.

Desgraciadamente, el síndrome del desconcierto se ha extendido. Seguramente, la salud institucional de nuestro País tiene un amplio camino de mejora. Pero pocos dudan de que el proceso estatutario, en particular todo lo relacionado con el recurso interpuesto contra el Estatuto de Autonomía de Cataluña, ha hecho flaco favor a la posición institucional del Tribunal Constitucional. En cualquier caso, la posición en la que situaba a este órgano no era motivo de envidia. Un texto rodeado de la más agria controversia política se sometía a su dictamen. Nada ayudaba. Desde taxativos pronunciamientos gubernamentales eliminando cualquier duda a descalificaciones globales de la oposición pasando por la intermitente pero constante amenaza de rebeldía

59 El referéndum sobre la independencia de Cataluña celebrado en la localidad de Arenys de Munt el 13 de septiembre de 2009 es un ejemplo del tipo de actos frente a los que parece que el Estado tenga respuesta. Lo que ese día pudo parecer anecdótico, no lo será tanto si el ejemplo se generaliza.

60 Sobre partidos y Estado autonómico, puede verse: J.J. SOLOZÁBAL ECHAVARRÍA, Partidos nacionalistas y partidos nacionales en el Estado autonómico en Nación y Constitución..., ob. cit., págs. 331-243. 
frente a una sentencia siquiera meramente interpretativa realizada desde distintas voces del espectro político catalán. Por si ello fuera poco, los continuos rumores sobre un pronunciamiento siempre inmediato, y que se ha demorado excesivamente, han acabado por provocar una sensación de inevitable debilitamiento del primer intérprete constitucional.

Sin poder profundizar en cuestiones que sin duda lo exigirían, sí resulta preciso advertir sobre la gravedad de la contraposición realizada en algunos ć́rculos entre el principio democrático y el principio de legalidad ${ }^{61}$. No se trata de un debate entre principio democrático y principio de legalidad, debate falso por muchos motivos. La defensa de la Constitución no está sólo anclada en el principio de legalidad. También tiene como uno de sus cimientos la protección del propio principio democrático.

Ya se ha visto que algunas de las paradojas que alumbran la idea de desconcierto tienen raíces antiguas. También la que vendré en denominar paradoja administrativa. Hay algo que parece mostrar que, a pesar de todo, muchos de los agentes implicados no acaban de creerse el modelo de descentralización al que se ha llegado. El funcionamiento de las respectivas administraciones públicas ilustra de manera significativa sobre este punto. Así, es difícil encontrar explicación, si no es bajo las premisas usadas para explicar el desconcierto, a que el Estado mantenga un número de funcionarios muy elevado y en crecimiento o que se creen muy recientemente ministerios como el de Vivienda o Igualdad, mientras perviven otros como Agricultura o Educación. Además, no es sólo que existan como referencia necesaria, con un núcleo de funcionarios. Es que sus estructuras administrativas siguen siendo, al menos en muchos casos, homologables con las de los primeros años del desarrollo constitucional.

Pero no sólo el Estado está aquejado de patologías en la esfera administrativa. Muchas Comunidades Autónomas, en este punto sí hay notables diferencias entre unas y otras, aun teniendo una muy notable estructura administrativa, siguen teniendo en el aparato burocrático estatal una referencia ineludible, de la misma manera que aplican en muchas ocasiones, de manera no siempre exenta de problemas, normas del Estado. Aunque pueda sonar a extravagancia, es lo cierto que uno tiene en ocasiones la impresión de que en algunas Comunidades, también depende de los organismos, asusta el volumen competencial adquirido o no se acaban de perder hábitos que, no puede olvidarse, tienen profundas raíces históricas.

Así, no extraña que en determinadas materias que en teoría son competencia exclusiva de las Comunidades Autónomas, el Estado siga poseyendo no sólo una estructura contundente sino ejerciendo muchas y significativas atribuciones. Turismo o agricultura sería tan sólo un ejemplo. Baste decir que cualquier ob-

61 Si esta tesis se podía leer en el mencionado artículo de J. Ramoneda, también ha encontrado eco en la doctrina (J. PÉREZ ROYO, La última palabra, El País, 4 de septiembre). Sobre la situación en la que el Tribunal Constitucional aborda la resolución de los recursos planteados contra el Estatuto de Autonomía de Cataluña, P. CRUZ VILLALÓN, El estado del Tribunal Constitucional, Claves de Razón Práctica n. ${ }^{\circ}$ 191, págs. 4-12. 
servador neutral concluye que la política turística española de los últimos años ha tenido su origen en dependencias estatales, con colaboración en su formulación de diversa intensidad por parte de las Comunidades Autónomas.

Acercándome a páginas conclusivas, es hora de traer a colación la voz federal, siquiera sea para llamar la atención sobre uno más de los elementos de desconcierto que domina el modelo territorial. En este caso se trata de concepciones globales, en último caso, porque no decirlo, ideológicas. Así, la apuesta o no por un modelo federal en la organización territorial del poder es una de aquellas decisiones fundamentales a las que ha de enfrentarse un constituyente. En el caso del constituyente de 1978, la voz, repetida en la calle e incluso en los congresos de los partidos, apenas podía tener reflejo en los debates parlamentarios. La cuerda no podía tensarse y para algunos bajos esas letras se escondía una amenaza más o menos intensa a la unidad de la Nación. A la postre, como se vio, el constituyente adoptó la única decisión que podía y sobre la que si había acuerdo casi universal, la de optar por un modelo de descentralización política, basado a grandes trazos en las líneas generales del modelo regional y dejando para tiempos venideros su concreción ${ }^{62}$. Los años pasaron y, como se vió, la descentralización del Estado llegó a un punto en el que éste podía ser descrito como federal sin violentar na$\mathrm{da}^{63}$. Pero, y he aquí que volvemos a encontrarnos con una de esas paradojas de tan difícil explicación y que tanto caracterizan a nuestro Estado, no sólo ningún sujeto político lo reivindica en voz alta sino que sigue condenado al ostracismo. Unos, que antaño lo defendían con entusiasmo o bien lo han simplemente olvidado o bien lo consideran radicalmente insuficiente en el marco de sus actuales aspiraciones de autogobierno. Otros, que han aprobado textos estatutarios que no encajarían por exceso en muchos Estados federales, siguen viendo en la misma una puerta abierta a los peores fantasmas. Es cierto que desde la doctrina se han alzado voces significativas reclamando la federalización efectiva del Estado ${ }^{64}$. Pero el silencio que las acompaña sólo

62 En este sentido apunta también SANTIAGO MUÑOZ MACHADO, ob. cit., Vol. I, pág. 182

63 Así, F. de CARRERAS subraya como el Estado, a fecha de 2003 era estructuralmente federal pero funcionalmente no por culpa tanto de las rémoras de la cultura política centralista como de una visión nacionalista de la organización territorial extendida a casi todas las Comunidades Autónomas (F. de CARRERAS, La reforma territorial: el cierre del modelo, en La reforma del Estado autonómico español y del Estado federal alemán, ob. cit., pág. 103). Por su parte, Eliseo Aja definió el Estado español en esa misma fecha como "un Estado federal con hechos diferenciales" (E. AJA, El Estado autonómico. Federalismo y hechos diferenciales, ob. cit., págs. 51-54). También Blanco Valdés ha descrito el Estado español como federal (R. BLANCO VALDÉS, Nacionalidades bistóricas y regiones sin bistoria, ob. cit., págs. 84.92). desde fuera de nuestras fronteras, también es común entender que el Estado autonómico ha derivado hacia un modelo federal. Así, Watts no duda en estudiar España como un Estado federal en su análisis comparado del federalismo (R.L. WATTS, Sistemas federales comparados, ob. cit.).

64 Así, entre otros, J. GARCÍA ROCA, El riesgo de la generalización de la asimetría en las reformas estatutarias, ob. cit., pág. 110; F. de CARRERAS, La reforma territorial: el cierre del modelo, ob. cit., págs. 124-125; J.J. SOLOZABAL ECHAVARRÍA, La reforma estatutaria en clave federal, ob. cit., págs. 371-382; J. PEMÁN GAVÍN, El sistema español de autonomías territoriales, ob. cit., pág. 36. 
viene a refrendar la profundidad de la paradoja. Un silencio que muchas veces hace pensar que lo que en realidad se desea evitar es un debate riguroso y global, un intento de construir soluciones y resolver problemas, es decir, evitar hacer política con mayúscula, olvidando las pequeñas exigencias del día a día. Y cabe advertir inmediatamente que no se trata de mero nominalismo. Tampoco se le puede restar valor al objetivo por la coincidencia antedicha en que nuestro Estado cumple con los canónes más generales del modelo federal. Levantar el velo, describir la realidad como es, normarla, serían argumentos suficientes. Pero la federalización expresa del Estado iría necesariamente más allá. Cubriría no sólo los alarmantes defícits de integración del modelo vigente, sino que sería una espléndida ocasión para rearmar ideológicamente al Estado y divulgar una cultura política de respeto a la unidad y diversidad que tanto se echa de menos.

\section{V.2. La posición de las Comunidades Autónomas}

Llegados a este punto, ensayado un mínimo acercamiento al Estado resultante de la evolución del proceso de descentralización política, parece preciso completarlo con una mirada al presente de las Comunidades Autónomas. No es la menor de las advertencias a realizar el recordar la heterogeneidad de las mismas. Diversidad debida no sólo a los respectivos marcos jurídicos sino también relacionada con otras causas como las condiciones preexistentes, la distinta fortuna de la afirmación autonómica o el diferente acierto de sus correspondientes dirigentes políticos. Así, las afirmaciones que siguen pecarán de una inevitable generalidad que sin duda conllevará a necesarias discrepancias en el juicio. Por ello mismo, procuraré refugiarme en reflexiones con la mayor vocación de universalidad posible, aun a sabiendas que puede echarse en falta mayor concreción.

El examen de ese presente ofrecido por el conjunto de las diecisiete Comunidades Autónomas y por cada una de ellas en singular, podría ser abordado desde consideraciones diversas. Desde la administración; desde la afirmación política de la autonomía; desde la percepción ciudadana o desde la evaluación de las diferentes políticas públicas, cabe analizar éxitos y fracasos del Estado autonómico en lo que es su última y necesaria manifestación, las Comunidades Autónomas. Vuelve a ser preciso recordar que el juicio que se realiza debe asumir como premisa de difícil discusión el éxito global del modelo. El mero hecho de haber transformado las viejas estructuras centralistas en un Estado fuertemente descentralizado con afirmación paritaria de la unidad y la autonomía, mantenimiento y progreso de las distintas políticas públicas y en un marco general de crecimiento económico, justifican la contundencia de la afirmación.

Pero, se recuerda, no es el pasado inmediato lo que puede llamar a inquietud al observador de la evolución jurídica y política del Estado. Es el futuro derivado de lo que se ha venido a denominar aprobación de los Estatutos de Autonomía de segunda generación. Como se ha indicado, el conte- 
nido de esos Estatutos y las premisas del Estado frente a los mismos y su desarrollo obligan a mirar con cautela el devenir inmediato de las dinámicas propias de un Estado descentralizado. En ese punto, resulta preciso referirse en el análisis del presente de las Comunidades Autónomas tanto a una importante paradoja sociopolítica como a lo que parece, sin más, una contradicción de las élites dirigentes que impulsaron la aprobación de los mencionados Estatutos.

La paradoja sociopolítica no es otra que la aparente contradicción entre el sentir ciudadano y la agenda de las direcciones de los partidos que impulsaron las reformas. Me refiero, claro está, a la indiferencia generalizada con la que los ciudadanos siguieron el proceso de aprobación de los nuevos Estatutos que, recuérdese, no fue precisamente pacífico en el orden político. En la mayoría de las encuestas, los ciudadanos de las seis Comunidades Autónomas que finalmente han aprobado nuevo Estatuto no consideraban entre sus primeras prioridades, ni siquiera entre las más relevantes, el incremento de las cuotas de autogobierno ${ }^{65}$. Lo más que podía percibirse es un sentimiento generalizado de que la autonomía debía ser equivalente en todas las Comunidades Autónomas. Hay que advertir que la afirmación anterior era incluso predicable para Cataluña en la que tampoco la reforma del Estatuto de Autonomía parecía estar entre las principales preocupaciones de sus ciudadanos, si bien ello era compatible con el crecimiento, como se dijo, de una sensación generalizada de descontento con la situación existente. En todo caso, la muy baja participación en los referéndums que sirvieron para la aprobación definitiva de los textos andaluz y catalán, casi escandalosa en el primer supuesto, parecen refrendar esa disintonía profunda entre políticos y ciudadanos $^{66}$. Algo que se corroboraría por el hecho de que ninguno de los otros cuatro textos incluyese el referéndum para su aprobación ni, incluso, lo previese como necesario para el futuro.

Evidentemente, las explicaciones que pueden darse a lo anterior son muy diversas. Como también evidentemente se puede discrepar y considerar que desde los partidos políticos sólo se siguió los deseos mayoritarios de los ciudadanos. En mi opinión, sí es posible coincidir en que ese proceso de reformas no fue un proceso iniciado a impulsos de los ciudadanos sino de las élites políticas. Y si bien se podría alegar que ello es siempre así en esta materia, lo cierto es que basta comparar este tiempo con el del inicio del proceso autonómico para comprender la existencia de significativas diferencias en el desarrollo de un proceso similar.

Arriesgando explicaciones, me atrevería a señalar dos como fundamentales. Por un lado, y pienso que en primer lugar, creo que puede aludirse a la satisfacción generalizada de los ciudadanos con el nivel de autogobierno

65 En general, la preocupación e interés por la reforma de los Estatutos fue muy bajo en toda España. En una encuesta del CIS de mayo de 2008, sólo el $0.1 \%$ de los españoles situaba la reforma de los Estatutos de Autonomía entre sus preocupaciones

66 La participación en el referéndum de Andalucía fue del 36,28 \% y en el que refrendó el texto catalán del 48,85\%. 
alcanzado y con el Estado resultante. Me parece que es una afirmación generalizable a la práctica totalidad de las Comunidades Autónomas, aunque, como resulta evidente, pueda exigir de matizaciones en relación con Cataluña y País Vasco. Matizaciones que, sin embargo, no creo que llegasen a afectar a la esencia de la afirmación. Circunscribiéndome al supuesto catalán, que es el que interesa a estas páginas, me cuesta pensar que los problemas surgidos no hubiesen podido tener solución desde planteamientos políticos más comúnmente respetuosos y deseosos realmente del acuerdo. Recuérdese en este momento que al comienzo de la segunda Legislatura del Presidente Aznar, el Gobierno de la Generalitat entonces presidida por el líder de CIU, Jordi Pujol, ni siquiera llegaba a plantear como inexcusable la reforma del Estatuto. Fundamentalmente demandaba una comprensión diferente del desarrollo de determinados aspectos de la autonomía y en particular del modelo de financiación. Las negativas a su demanda y el hecho de que su sucesor, paradójicamente de un partido al menos no formalmente nacionalista, elevase sustancialmente la radicalidad de las demandas, acabaron por propiciar un clima de auto alimentación de la tensión política en el que lo que debía ser un necesario, siempre complejo, acuerdo, acabó en el callejón sin salida, con todas las partes insatisfechas que es el tiempo presente.

Pero si en Cataluña podría debatirse sobre el alcance del nivel de satisfacción de sus ciudadanos con el autogobierno que ejercían sus instituciones, difícilmente me parece que pueda trasladarse la misma afirmación a los de Andalucía, Aragón, Comunidad Valenciana, Islas Baleares o Castilla y León. Es posible afirmar con cierta rotundidad que estos se encontraban satisfechos con el modelo de organización territorial existente y que para la inmensa mayoría se trataba ya de un debate superado. La autonomía tenía más que ver con la gestión de sus más inmediatos intereses que con posibles reivindicaciones de futuro, y, por supuesto, más que con vagas y abstractas referencias identitarias. Las respectivas Comunidades Autónomas habían afirmado con claridad su ser político en el mapa español y pocos eran los hacían cuestión de la identidad colectiva. Por otra parte, desde una visión más pragmática, pocas competencias que a los ciudadanos afectasen directamente podían ser ya recabadas por sus poderes autonómicos. En todo caso, podría alegarse una común preocupación por la financiación siempre vinculada al debate de la emulación y a la postre, seguramente, causa directa de la reforma de los Estatutos.

Pero, inevitablemente, el ambiente descrito acerca a la segunda de las causas de esa distancia de los ciudadanos que deseaba citar. Me refiero a la fatiga. Si la fatiga con el escenario colectivo de lo político es algo comúnmente descrito por comentaristas de distinta procedencia, resulta inevitable que un debate como el que ha protagonizado el modelo territorial en los últimos años se contagie de la misma. Como se indicó, las preocupaciones fundamentales de los ciudadanos eran la mejora de políticas públicas como sanidad o educación; de las infraestructuras colectivas o por los distintos avatares económicos. El debate que se planteaba resultaba demasiado abstracto 
y lejano. Por otra parte, tampoco desde la clase política se hizo en la mayoría de las Comunidades Autónomas suficiente pedagogía. No llegó a explicarse con claridad las razones que abonaban la necesidad del cambio y las eventuales consecuencias positivas para los ciudadanos. Un ejemplo ilustrativo de ello fue el hecho de que la inclusión de tablas de derechos y libertades en los nuevos Estatutos si bien ocasionó un intenso debate doctrinal, no llegó a transcender a la ciudadanía que permaneció sustancialmente ajena a algo que en teoría resultaba de gran importancia para sus intereses cotidianos ${ }^{67}$.

Precisamente, la referencia a estas tablas de derechos y libertades acerca a un dato significativo que no debe ser obviado en el análisis que se propone. Transcurridos más de dos años desde la aprobación de los nuevos Estatutos, un análisis de lo acontecido en las diferentes Comunidades Autónomas demuestra que el desarrollo de los mismos ha sido muy escaso. De alguna manera, es como si una vez aprobado el nuevo texto estatutario, se hubiese cumplido la formalidad necesaria y el tema se hubiese cerrado. Desde luego, el debate catalán con la Sentencia del Tribunal Constitucional pendiente o el derivado del nuevo modelo de financiación matizan la afirmación anterior. Pero creo que la misma es sustancialmente válida en la mayoría de las Comunidades Autónomas. De hecho, las elecciones autonómicas de 2007, muy cercanas a la aprobación de los nuevos textos, dejaron en evidencia la relatividad incluso política del debate y la conciencia por parte de los partidos de que no se trataba de un tema de especial interés para los ciudadanos. En las correspondientes campañas, el modelo autonómico derivado del nuevo Estatuto fue en general simplemente ignorado y apenas hubo referencias al mismo.

El presente de las Comunidades Autónomas puede y debe ser evaluado desde otras perspectivas. Como se indicó, la eficacia y eficiencia de las administraciones públicas autonómicas para la gestión de las políticas públicas se antoja como uno de los parámetros fundamentales de enjuiciamiento. Se trata de una cuestión que requiere de un examen que escape de apriorismos y desde análisis empíricos pueda aportar veres necesarios al estudio del Estado autonómico. En su momento, se subrayó como un éxito del modelo español

67 El debate sobre este extremo ha sido uno de los más ricos: L.M. DÍEZ-PICAZO, ¿Pueden los Estatutos de Autonomía declarar, derechos, deberes y principios?, REDC n. ${ }^{78}$, 2006, págs. 63-75; L.M. DÍEZ-PICAZO, De nuevo sobre las declaraciones estatutarias de derechos: respuesta a Francisco Caamaño, REDC n. ${ }^{\circ}$ 81, 2007; V. FERRERES COMELLA, Derechos, deberes y principios en el nuevo Estatuto de Autonomía de Cataluña, CEPC, 2006, págs. 9-37; P. BIGLINO CAMPOS, Los espejismos de la tabla de derechos en Derechos, deberes y principios en el nuevo Estatuto de Autonomía de Cataluña, ob. cit., págs. 39-61; M.A. APARICIO PÉREZ; M. BARCELÓ SERRAMALERA, Los derechos públicos estatutarios, www.fundacionmgimenezabad.es, 2007; M. CARRILLO, Los derechos, un contenido constitucional de los Estatutos de Autonomí, REDC n. ${ }^{\circ}$ 80, 2007, págs. 49-73; F. CAAMAÑO, Si, pueden (Declaraciones de derechos y Estatutos de Autonomía), REDC n. ${ }^{\circ}$ 79, págs. 33 y ss; E. EXPÓSITO, La regulación de los derechos en los nuevos Estatutos de Autonomía, ob. cit. Paradójicamente, como ha indicado Canosa Usera, ha sido ésta una cuestión que ha suscitado más debate doctrinal que político (R. CANOSA USERA, La declaración de derechos en los nuevos Estatutos de Autonomía, Teoría y Realidad Constitucional, n. ${ }^{\circ}$ 20, 2007, pág. 62). 
de descentralización política la continuidad sin traumas en la gestión de las más importantes políticas públicas e, incluso, su mejora paulatina. Al respecto, hay que valorar como muy positivo el efecto contagio derivado del propio deseo de emulación y que lleva a que pocos de los avances que puedan alcanzarse en una Comunidad Autónoma no sean contagiados al resto. Dicho esto, resulta también forzoso aludir a facetas no tan positivas.

En concreto, creo que puede realizarse una referencia expresa a los defectos existentes en el modelo de administración pública desarrollado por las Comunidades Autónomas. Lejos de perseguir el desarrollo de modelos originales que superasen viejos defectos de la administración central, muchas veces atada a los mismos por sus propias inercias, ha sido frecuente que las Comunidades Autónomas desarrollen modelos administrativos lastrados por esas mismas inercias e, incluso, agravadas por una fuerte tendencia a la confusión entre las esferas políticas y administrativas, así como por la oscuridad en aspectos esenciales de la gestión administrativas. El resultado ha sido el desarrollo de diecisiete nuevas administraciones, radicalmente separadas entre sí y con frecuentes problemas tanto de gestión como de transparencia. La falta de relación entre las distintas administraciones no es sólo un problema que afecte al modelo propiamente dicho de relaciones intergubernamentales. Afecta, también al desarrollo profesional de esas administraciones y de la estructura administrativa del Estado en su conjunto. La práctica imposibilidad de la movilidad de funcionarios, por citar sólo un ejemplo, no es sino uno de los síntomas de un empobrecimiento general de la estructura administrativa del Estado en su conjunto

Para finalizar este somero análisis, creo que es preciso hacer referencia a una cuestión trascendental. Me refiero a la distribución de la responsabilidad en el Estado autonómico. Ha sido una de las banderas ideológicas del mismo la dilución de la responsabilidad de las instituciones autonómicas en demérito de un Estado central que siempre resulta último responsable, por supuesto, sólo de problemas y contrariedades. La afirmación de una cultura social y política de la identidad autonómica sobre un ser y un actuar ajenos al error y al fracaso ha sido general a todas las Comunidades Autónomas y a todas las formaciones políticas. Posiciones sociales y políticas han confluido en esta visión que facilitaba la consecución de acuerdos. Las visiones críticas han sido mayoritariamente desterradas y el pensamiento heterodoxo se ha marginado, cuando no autoeliminado, como en pocas ocasiones. Mientras, la adición de círculos y confusiones sólo han hecho agravar las cosas. Hoy no es posible trazar una línea clara de las responsabilidades que corresponden a cada escalón administrativo. Más allá de lamentos y críticas defensivas, algo debería hacer reflexionar al respecto que el informe previo del Comité Olímpico Internacional sobre la candidatura de Madrid 2016 estime como uno de los principales problemas de la misma la confusión entre las distintas administraciones.

Repito que hay muchos motivos para la satisfacción. Pero también hay problemas y hay señales evidentes de que estos pueden agravarse con un 
mapa jurídico y político bastante más complejo como es el resultante de la aprobación de los Estatutos de Autonomía de segunda generación. Negar la existencia de esos problemas, la posibilidad de que surjan nuevos o se agraven los existentes, es simplemente irresponsable. Como es natural, las Comunidades Autónomas no son una arcadia política y durante estos años han generado sus vicios y rutinas. Sólo desde una reflexión crítica podrá contribuirse a su mejora y, con ella, del Estado en su conjunto al servicio del único interés legítimo para un gobernante, el de sus ciudadanos. Desde esa perspectiva, resulta evidente que las Comunidades no sólo deberán realizar ese examen crítico sino que deberían atender a la visión del Estado en su conjunto que representan. Sólo desde la suma, desde una mutua lealtad y comprensión será posible responder a los nuevos y formidables retos atendiendo a la distribución de las mismas de acuerdo con las escalas necesarias

\section{A MODO DE CONCLUSIÓN. UN ENSAYO DE EVALUACIÓN VALORATIVA}

Como se ha intentado explicar, la evolución del modelo territorial español es más compleja de lo que en demasiadas ocasiones se explica. El protagonismo del debate sobre los nacionalismos vasco y catalán, sin duda trascendente, ha llegado a ocultar aspectos muy importantes de esa evolución. Simplificar y resumir la misma no es sencillo ni seguramente posible. Baste indicar como postulado por todos asumible que durante estos años se ha producido un paulatino adelgazamiento del Estado correspondido inevitablemente por un fortalecimiento político y administrativo de las Comunidades Autónomas.

En ese proceso, la aprobación de los Estatutos de segunda generación supone algo más que un salto cuantitativo. Supone una verdadera transformación cualitativa del Estado ${ }^{68}$. Que la misma haya sido negada por las instancias del poder central del Estado no ha sido el menor de los problemas. No reconocer la dimensión del cambio acaecido con la aprobación de los nuevos Estatutos inevitablemente trae confusión y, sobre todo, desampara al propio poder central. Desde luego, esta expresión ha de entenderse en sus justos términos. Antes se aludió a un proceso paulatino de adelgaza-

68 Si bien alrededor de esta afirmación se pueden encontrar los naturales matices dentro de la doctrina, pocos son los que niegan lo que de sustancial tienen los cambios en el modelo de organización territorial como consecuencia de la aprobación de los nuevos Estatutos de Autonomía. Bien para criticar el proceso bien para respaldarlo, la coincidencia en la importancia de los cambios es notable. Al respecto: L. PAREJO ALFONSO, La organización territorial del Estado ¿Proceso a continuar u obra a culminar?, RGDA n. ${ }^{\circ} 12$, 2006; J. CORCUERA ATIENZA, Las reformas del modelo territorial en Alemania y España: dos lógicas diferentes, ob. cit., pág. 65-67; G. JAUREGUI, Las reformas del Estado autonómico español: un primer balance de urgencia en La reforma del Estado autonómico español..., ob. cit., pág. 91; C. VIVER I PI I SUNYER, ¿Grandes reformas o pequeños pasos? Una perspectiva desde Cataluña en La reforma del Estado autonómico español..., ob. cit., págs. 31-42; R. BLANCO VALDÉS, El largo viaje de España: de la invención del Estado autonómico al impulso hacia la confederación, ob. cit. 
miento del Estado. Proceso que, puede decirse, no se ha correspondido con un debilitamiento sustancial del mismo. De forma nuevamente paradójica, el Estado ha continuado siendo una supraestructura de referencia en materias incluso de competencia exclusiva de las Comunidades Autónomas. En muchas Comunidades Autónomas, y esta sí es una referencia política notable entre unas y otras, el Estado, su colaboración sino ayuda administrativa e incluso sus normas en materias en principio ajenas, siguen siendo modelo indiscutible. Por su parte, el Estado en una actitud que, con razón, algunos han calificado de desleal para el conjunto del modelo, excede su espacio natural. Incluso, el espacio que en los últimos tiempos ha venido en defender solemnemente. Ejemplo de ello serían el procedimiento que acabó con la aprobación de una Ley de la dependencia o la creación del Ministerio de la Vivienda.

Pero si es cierto que el denominado Estado central sigue siendo fuerte en lo administrativo, que sus funcionarios son numerosos o que la Unión Europea ha contribuido a paliar el debilitamiento derivado del proceso de transferencias a las Comunidades Autónomas, también parece que lo es que sí ha existido un debilitamiento ideológico del mismo. Debilitamiento que a la postre se antoja una de las consecuencias más significativas del desarrollo del Estado autonómico y, en particular, de la aprobación de los nuevos Estatutos de Autonomía.

Durante el proceso de elaboración y posterior aprobación del nuevo Estatuto de Autonomía se puso de moda el debate político alrededor de la expresión "España se rompe». Desde luego, la fortuna no acompañaba esas palabras y creo que pocos ciudadanos llegaron a sentirse directamente compelidos por la misma. Pero no más afortunadas fueron las contestaciones a la misma. Contestaciones porque en pocas ocasiones pudieron oírse de una y otra parte verdaderos argumentos. Las respuestas se limitaban a negar cualquier incidencia de los nuevos Estatutos sobre la estructura estatal y a realizar una descalificación apriorística de los temores que encerraban la frase susodicha.

Pero si bien es posible descalificar por excesiva la afirmación antedicha, no puede negarse que los nuevos Estatutos inciden en la estructura del Estado y lo hacen desde la premisa de un debilitamiento ideológico notable del mismo, especialmente el texto catalán que tiene en este punto, más allá de problemas jurídicos, su verdadero núcleo. Algo, por lo demás, no negado en ningún momento por sus partidarios. Si todos los Estatutos se han aprobado, con mayor o menor intensidad, en una afirmación de la propia identidad, favoreciendo una visión del Estado como el otro, en el texto catalán esto alcanza una intensidad notable que inevitablemente alcanza a la definición del Estado español. No se trata de una cuestión concreta. Se trata de una suma que no deja espacio para una visión diferente. Nación, fundamento del autogobierno en los derechos históricos, símbolos nacionales, bilateralidad, lengua propia... son sólo eslabones de una cadena que tiene una clara inspiración ideológica. Ninguna referencia a lo que une, constancia en lo que 
separa y distingue. No se puede, hay que insistir en ello, ver las distintas partes del texto de forma aislada. Ello puede servir para el análisis concreto de su encaje en el ordenamiento constitucional. Pero más allá de ello está el significado global de un texto que expresa una voluntad manifiesta como claramente se deduce de los antecedentes parlamentarios y de la opinión reiteradamente expresada por la inmensa mayoría de las formaciones políticas catalanas.

Debe quedar claro que nada puede oponerse ideológicamente a los posicionamientos que defienden esas o tesis más radicales. Lo extraño, lo difícilmente comprensible, es que desde los órganos encargados de velar por las estructuras comunes, no se quiera ver y no se oponga con la misma firmeza los argumentos que favorecen el desarrollo de la visión del Estado que en un modelo de descentralización más o menos intensa se encontraba en la Constitución. Si bien coyunturas políticas explican algunas cuestiones, lo cierto es que en el fondo late algo más complejo, algo que podría denominarse la interiorización por las formaciones políticas nacionales de ese debilitamiento ideológico del Estado. Así, de manera una vez más contradictoria, se entiende y se comprende la defensa de posiciones nacionalistas en los territorios autonómicos y, simultáneamente, se huye de afirmaciones mínimas en relación con cuestiones como la lengua, los símbolos nacionales o los curriculum educativos. Inevitablemente hay que aclarar que no se trata de oponer un nacionalismo a otro nacionalismo, argumento reiterada y torticeramente utilizado. Se trata, tan sólo de mantener la vigencia del Estado común como casa de ciudadanía y servicio público. Para ello, no se puede cerrar los ojos ante posiciones, legítimas, sí, pero que persiguen un debilitamiento irreversible de las estructuras estatales que finalmente hagan posible deseos de secesión que hoy no resultan viables porque, no se olvide, son minoritarios entre los ciudadanos. Resumido en términos, ahora sí, puramente políticos, si es legítimo defender posiciones políticas secesionistas, no sólo será legítimo sino que resultará una obligación de los partidos nacionales una actitud activa frente a las mismas.

Desconocer que el Estatuto de Autonomía de Cataluña es un paso en esa dirección creo que es un error. Como se ha indicado, no se trata de cuestiones concretas por muy importantes que sean. Es la suma que vertebra todo el texto. Una suma que no puede ser medida sólo en términos de presente. Las normas han de ser valoradas por su potencia. Hay que leer sus palabras, sobre todo en textos de esta naturaleza, pensando en contextos futuros. Desde luego, no es la labor que hoy corresponde al Tribunal Constitucional al que sólo le vincula la literalidad del texto estatutario. Pero esa potencia es una responsabilidad a la que ningún político puede ser ajeno.

Si la referencia al debilitamiento ideológico del Estado acaba por concentrarse inevitablemente en el texto catalán, no puede obviarse la suma derivada del resto de los textos, aprobados, recuérdese con acuerdo en todos los casos de las dos grandes formaciones políticas nacionales. Es claro que sus premisas ideológicas son diferentes. Nada más evidente que la literalidad 
del Estatuto de Autonomía de Andalucía que no se cansa en reiterar los vínculos indisolubles de la Comunidad Autónoma con España. Pero, más allá de esta muy notable diferencia, no puede dejar de repararse en que, como se indicó, los mismos están redactados desde una clara afirmación identitaria y, especialmente, que, desde la suma de sus contenidos, acaban también por debilitar no sólo materialmente sino también ideológicamente al Estado. Puede ser una erosión débil o ser más intensa. Pero no es posible negar que se trata de una suma aun en proceso que, por otra parte, parece haberse instalado como irreversible en la conciencia política.

Desde las afirmaciones anteriores, llego al juicio que estimo más significativo sobre el proceso derivado por la aprobación de los nuevos Estatutos. Los mismos, en ocasiones de forma consciente, en otras de manera inconsciente, han tensionado de manera centrípeta al Estado hasta el extremo de dibujar una nueva forma de organización territorial. El dibujo ideológico del Estado que resulta de los mismos; los nuevos contenidos que transcienden con amplitud el ámbito competencial o el hecho de que la heterogenidad del mapa autonómico sea una condición irreversible de esa organización, serían las premisas que sostienen esa afirmación. Mas si esas decisiones podrían ser discutibles en si mismas consideradas, lo que resulta más que sorprendente es que a las mismas se haya llegado sin hoja de ruta, que desde el Estado se haya impulsado un proceso de consecuencias tan notables sin reparar en lo que éste suponía. De hecho, como se indicó, hay claros indicios de que a día de hoy se sigue sin ser consciente del alcance de la operación realizada.

Una valoración final del proceso pasa inevitablemente por un juicio político. Desde esta perspectiva, en su más honda dimensión, no puede decirse sino que el proceso ha sido un rotundo fracaso ${ }^{69}$. Desde el día siguiente a la aprobación del Estatuto de Autonomía de Cataluña las fuerzas políticas catalanas, incluso aquellas que impulsaron el texto final, señalaron su disconformidad con el mismo y que se trataba sólo de una etapa, que más pronto que tarde habría que iniciar un nuevo proceso de reforma o bien directamente el camino a la secesión. Desde entonces, la sensación de descontento y rechazo al texto aprobado no ha hecho sino acentuarse. Ni siquiera la aprobación de un nuevo modelo de financiación claramente inspirado en los preceptos estatutarios parece haber cambiado esta percepción. Si el descontento y el rechazo es general entre las formaciones que lo aprobaron, no menor podía

69 Se trata de un juicio ya bastante extendido, tanto entre quienes han propugnado la necesidad de profundizar cualitativamente en el proceso de descentralización como en aquellos que han visto en este proceso serios problemas de encaje en el modelo constitucional (así: R. BLANCO VALDÉS, El largo viaje de España: de la invención del Estado autonómico al impulso hacia la confederación, ob. cit., pág. 14; G. JAUREGUI, Las reformas del Estado autonómico español: un primer balance de urgencia, ob. cit., pág. 93; F. DE CARRERAS, La reforma territorial: el cierre del modelo, ob. cit., págs. 123-124; J. PEMÁN GAVÍN, El sistema español de autonomías territoriales..., ob. cit, pág. 6. Una visión más optimista, sin ocultar los problemas en J. CANO BUESO, Una reflexión sobre el Estado autonómico, ob. cit) 
ser entre quienes lo rechazaron bien por excesivo bien por insuficiente. Lo cierto es que nadie está satisfecho. Sólo la grave crisis económica parece haber paliado esta decepción general.

Un debate que se reaviva en términos que sólo pueden ser denunciados como graves en relación con el esperado pronunciamiento del Tribunal Constitucional ante los recursos interpuestos por el Partido Popular y el Defensor del Pueblo. Desde el nacionalismo, incluso desde las instituciones catalanas, la defensa cerrada del texto aprobado se convierte en bandera y se discute la legitimidad del Tribunal Constitucional para pronunciarse sobre la constitucionalidad de una norma aprobada por dos Parlamentos y el pueblo de Cataluña. Incluso, como se vió, desde algún sector de la doctrina se llega afirmar que dadas las características del Estatuto de Autonomía, el Tribunal Constitucional no puede pronunciarse sobre él. De forma extremadamente grave, y creo que falsa, se oponen la legitimidad jurídica y la legitimidad democrática, legalidad frente a democracia, dialécticas que recuerdan inevitablemente momentos aciagos de la historia. Si resulta por evidente ocioso negar desde la legalidad constitucional esta línea argumental, mayor atención merece rebatir el denominado argumento democrático, es decir, la imposibilidad declarar inconstitucional una norma refrendada por el pueblo de Cataluña. Desde luego, la situación no es la mejor de las posibles. Instrumentos como el fenecido recurso previo de inconstitucionalidad habrían servido para evitar este tipo de debates. Pero lo cierto es que quienes argumentan el refrendo del pueblo de Cataluña, parecen desconocer que la Constitución es asimismo un texto refrendado y en esta ocasión por el conjunto del Estado. Entre otras cosas, el pueblo que la refrendó aprobó que existiese un órgano que garantizase su supremacía frente a cualquier norma que la desarrollase. Decir que el Tribunal Constitucional no puede pronunciarse sobre un Estatuto de Autonomía refrendado es tanto como alterar la voluntad también pronunciada en refrendo del pueblo español en su conjunto.

En todo caso, creo que hay que negar de raíz virtualidad a semejante debate. El mismo transciende los términos de la discusión sobre la forma de Estado para convertirse en un verdadero cuestionamiento vía hecho de todo el orden político y constitucional. Si se abriese camino la línea argumental aludida, resultaría a la postre muy difícil seguir sosteniendo un modelo de Estado basado en la primacía de la Constitución garantizada por el Tribunal Constitucional. Los argumentos para encontrar caminos similares se multiplicarían tanto como los posibles pronunciamientos populares sobre todas aquellas cuestiones de dudosa constitucionalidad. Bastaría a un gobernante avezado convocar un referéndum para vía hecho modificar incluso expresamente la Constitución.

A la espera del pronunciamiento del Tribunal Constitucional y de las eventuales reacciones, sólo resta realizar un postrer llamamiento a la claridad. Utilizando la idea del político quebeques, pienso que nuestro modelo territorial demanda urgentemente de la claridad. La exige en lo político y en su dimen- 
sión más estrictamente jurídica ${ }^{70}$. La construcción territorial del poder es a la postre un desafío político apasionante, uno de los mayores que le caben a una comunidad política. No basta actuar de acuerdo con la coyuntura. Se exigen ideas rectoras, saber lo que se desea para el todo y para las partes. Lo deben conocer los dirigentes políticos y con claridad deben explicarlo a los ciudadanos para que estos decidan, muestren su conformidad o su rechazo. Hay que levantar los velos, ver el Estado como es y así explicarlo. Con sus virtudes y defectos, necesidades y exigencias. Desde esa idea de claridad, se observa mejor la posición desequilibrada en la que el Estado como vocación política se encuentra frente a los deseos y voluntades nacionalistas.

Si la claridad es precisa en los objetivos e idearios políticos, no lo es menos en su concreción jurídica. Un modelo de por sí ya suficientemente complejo va a ver necesariamente incrementada esa complejidad por el proceso abierto con la aprobación de los nuevos Estatutos, pronunciamiento incluido del Tribunal Constitucional. Una dificultad que puede llegar a dificultar la gestión pública, acabando por tener incidencias en las distintas políticas públicas. Se hace precisa una parada que siente a las partes y permita una simplificación que cumpla varios objetivos. A saber. Por una parte, es necesario dotar a los operadores sociales, jurídicos, políticos y económicos de un marco normativo que sólo mantenga aquellas ambigüedades inevitables en un modelo descentralización política. Por otra, e íntimamente vinculado a aquella, es preciso definir con mayor claridad las distintas responsabilidades de las diversas administraciones públicas y transmitir esa definición a los ciudadanos que a la postre han de enjuiciar el actuar de sus gobernantes. Finalmente, habría que servirse de esa parada para construir de una vez por todas el modelo de relaciones intergubernamentales propio de un Estado como el español.

Con esas premisas, sólo una reforma de la Constitución para la federalización efectiva del Estado se presenta como vía de solución. Una reforma que no sólo devuelva claridad al modelo sino que contribuya a fortalecer los valores de ciudadanía propios del federalismo. La fortaleza de la unidad y la riqueza de la diversidad. Todo ello vivido más allá de la necesidad. No se trata de ser ilusos. Siempre habrá quien vea en ese Estado federal la ruptura de la unidad de la Nación y quien la conside insuficiente. Es lógico y legítimo. Pero hoy, en el conjunto del Estado y en todas y cada una de las Comunidades Autónomas, son los menos. El objetivo de los líderes políticos nacionales debe ser que su número no crezca. No es una tarea que permita mucha dilación. Se necesita ponerse a ella con inmediatez.

Desgraciadamente, los vientos que corren no invitan a pensar que será fácil siquiera intentar el diálogo que habría de llevar al comienzo del proceso de reforma constitucional. Ello sólo será posible desde un acuerdo previo sobre la voluntad de conformar una comunidad política. Por supuesto, es

70 Véase, S. DION, La politica de la claridad. Discursos y escritos sobre la unidad canadiense, Fundación Manuel Giménez Abad-Alianza Editorial, 2005, 371 págs. 
preciso realizar todos los esfuerzos posibles para que el número de aquellos que tengan esa voluntad sea el mayor posible. Pero, es preciso repetirlo, hay que tener claro que algunos no lo desean ni lo desearán. Qué legítimamente desean conformar Estados propios desde actuales territorios autonómicos. Con la misma legitimidad que respalda sus ideas, se les debiera excluir del proceso de construcción del Estado. El Estado sólo puede construirse a la postre con aquellos que quieren ser Estado. Desde esa premisa, ha sido viable y lo será, llegar a acuerdos con determinadas formaciones políticas. Pero no con otras. Construir el Estado pensando en su satisfacción se antoja no sólo un imposible en si mismo sino en un error de graves consecuencias.

España es una realidad federal que sólo ha adoptado del modelo la ideología y los instrumentos de descentralización. Ha olvidado los no menos importantes instrumentos e ideología de la unidad. Reparar este error se antoja como el primer paso para intentar entre aquellos que lo deseen resolver el apasionante reto de la organización territorial que ni desde la política ni desde la ciudadanía está resuelto.

TitLE The Autonomous State thirty years after.

AвSTRACT: In recent years the debate about the territorial organisation of the State has regained impetus, and today it is one of the principal, or even the most important of the challenges that our constitutional model has to face. Our current situation cannot be understood without looking back to the origin and evolution of our constitutional model. The following pages intend to remind us of the political, ideological and judicial premises of that evolution which, in turn, will allow us to make an attempt to evaluate what, for the model as a whole, are known as "second generation" Statutes of Autonomy. Specifically, it is defended that their approval causes a constitutional mutation of the model of territorial organisation, which is basically derived from the ideology that prevails in the Statute of Autonomy in Catalonia.

RESUMEN: En los últimos años el debate sobre la organización territorial del Estado ha recobrado impulso y es boy uno de los primeros, sino el primero, retos que tiene que afrontar nuestro modelo constitucional. El presente no puede comprenderse si no se recuerda el origen y evolución del modelo constitucional. Estas páginas pretenden recordar las premisas políticas, ideológicas y jurídicas de esa evolución para desde las mismas realizar un ensayo de valoración lo que para el modelo en su conjunto representan los llamados Estatutos de Autonomía de segunda generación. En concreto, se defiende que su aprobación tiene como consecuencia una mutación constitucional del modelo de organización territorial, derivada fundamentalmente de la ideología que preside el Estatuto de Autonomía de Cataluña.

Key words: Autonomía. Estatuto de Autonomía. Comunidad Autónoma. Estado autonómico. Organización territorial. Mutación constitucional.

Palabras clave: Autonomy. Statute of Autonomy. Autonomous Region. Autonomous State. Territorial organization. Constitutional mutation. 